\title{
A Physiological-Based Model for Simulating the Bioavailability and Kinetics of Sulforaphane from Broccoli Products
}

\author{
Quchat Shekarri and Matthijs Dekker*(D) \\ Food Quality and Design Group, Wageningen University and Research, P.O. Box 17, \\ 6700 AA Wageningen, The Netherlands; quchat.shekarri@wur.nl \\ * Correspondence: matthijs.dekker@wur.nl
}

check for updates

Citation: Shekarri, Q.; Dekker, M. A Physiological-Based Model for Simulating the Bioavailability and Kinetics of Sulforaphane from Broccoli Products. Foods 2021, 10, 2761. https://doi.org/10.3390/ foods10112761

Academic Editor: Didier Dupont

Received: 15 October 2021

Accepted: 8 November 2021

Published: 10 November 2021

Publisher's Note: MDPI stays neutral with regard to jurisdictional claims in published maps and institutional affiliations.

Copyright: (c) 2021 by the authors. Licensee MDPI, Basel, Switzerland. This article is an open access article distributed under the terms and conditions of the Creative Commons Attribution (CC BY) license (https:/ / creativecommons.org/licenses/by/ $4.0 /)$.

\begin{abstract}
There are no known physiological-based digestion models that depict glucoraphanin (GR) to sulforaphane (SR) conversion and subsequent absorption. The aim of this research was to make a physiological-based digestion model that includes SR formation, both by endogenous myrosinase and gut bacterial enzymes, and to simulate the SR bioavailability. An 18-compartment model (mouth, two stomach, seven small intestine, seven large intestine, and blood compartments) describing transit, reactions and absorption was made. The model, consisting of differential equations, was fit to data from a human intervention study using Mathwork's Simulink and Matlab software. SR urine metabolite data from participants who consumed different broccoli products were used to estimate several model parameters and validate the model. The products had high, medium, low, and zero myrosinase content. The model's predicted values fit the experimental values very well. Parity plots showed that the predicted values closely matched experimental values for the high $\left(r^{2}=0.95\right)$, and low $\left(r^{2}=0.93\right)$ products, but less so for the medium $\left(r^{2}=0.85\right)$ and zero $\left(r^{2}=0.78\right)$ myrosinase products. This is the first physiological-based model to depict the unique bioconversion processes of bioactive SR from broccoli. This model represents a preliminary step in creating a predictive model for the biological effect of SR, which can be used in the growing field of personalized nutrition.
\end{abstract}

Keywords: physiological-based model; sulforaphane; glucoraphanin; compartmental model; broccoli; bioavailability; myrosinase; parameter estimation

\section{Introduction}

To determine the bioavailability of bioactive compounds in foods, it is important to know its composition, structure, how it interacts with other food components, and its fate in the human body after being ingested. Isothiocyanates (ITC) are formed from precursors, glucosinolates (GL), which are found in broccoli and other types of brassica vegetables [1]. Numerous studies investigated the health effects of some ITCs. One such ITC is called sulforaphane (SR), derived from the GL glucoraphanin (GR). Sulforaphane is known to reduce the risk of cancer, and has cardiovascular and central nervous system protection benefits $[1,2]$.

Sulforaphane's health benefits have resulted in studies that investigated the physiological mechanisms involved in digesting plants that contain SR, and SR's absorption, metabolism, and excretion [3,4]. Glucoraphanin is converted to SR by plant endogenous myrosinase (MYR), a $\beta$-thioglucosidase hydrolase that catalyzes the removal of glucose to form an O-sulfated thiohydroximate intermediate (Figure 1). GLs and MYR are stored in separate compartments in the broccoli plant cells. Cell structure disruption, from processing (chopping, blanching, powdering etc.), mastication, or plant bruising, is required before MYR can bind GL to facilitate ITC formation [5]. Gut bacteria in the colon also have the capability to facilitate this conversion from GR to SR [6-14]. After ingestion, and transfer through the stomach, SR is absorbed in the intestinal tract into the blood, then distributed to various organs before it is eliminated from the body, mainly via renal excretion [15]. 
(A)

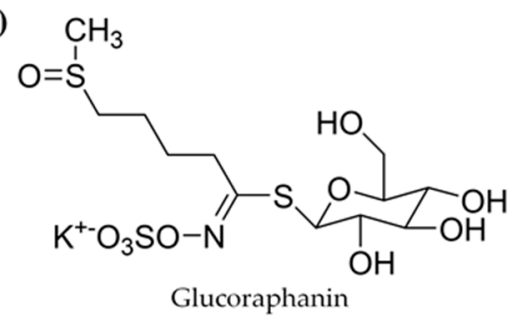

Glucoraphanin

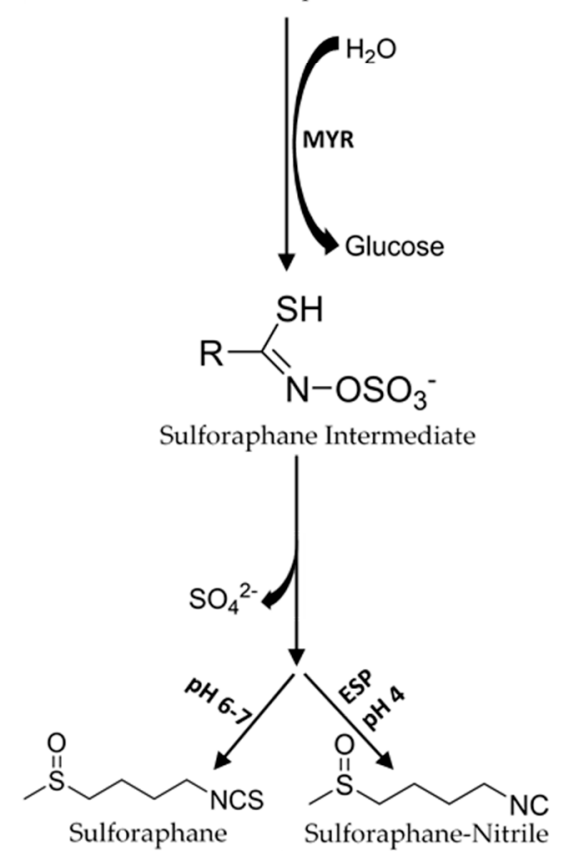

(B)

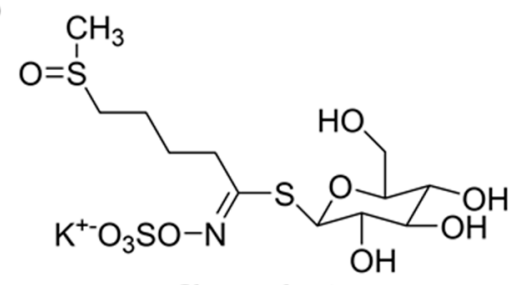

Glucoraphanin

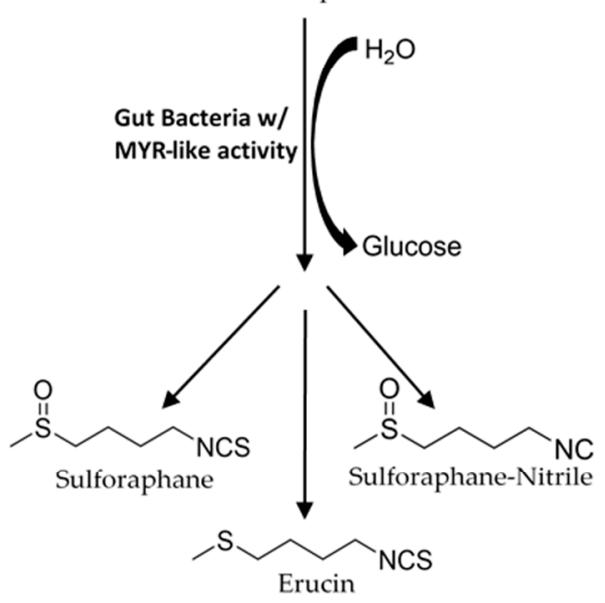

Figure 1. (A) In the mouth, myrosinase (MYR) converts glucoraphanin (GR) to an SR-O-sulfated thiohydroximate intermediate. Depending on $\mathrm{pH}$ conditions sulforaphane (SR) forms. SR-nitrile formation is preferred at low $\mathrm{pH}$ in the presence of epithiospecifier protein (ESP). (B) In the gut GR is converted to SR, SR-nitrile, and erucin by gut bacteria.

The bioavailability of SR is described as the fraction of the amount of SR that is ingested and/or formed in the body that reaches systematic circulation [3]. Related to bioavailability is bioaccessibility, which is the fraction of a compound that is released from the food and that reaches the absorption site. In the context of GLs, MYR and ITCs, the bioaccessible ITC is the fraction of ITCs released from the food matrix [3] or the fraction of GLs transformed to ITCs and released in the body. Bioaccessibility of ITCs is affected by the plant's inherent GL content (which varies from 47 to $806 \mathrm{mg} / 100 \mathrm{~g}$ fresh weight of broccoli [1]), processing, the food matrix [16-18], and the digestion $[17,19,20]$.

The bioaccessibility of ITC could increase or decrease depending on the type of processing. Chopping, blending, powdering are particle size reduction methods that rupture the plant tissue and allow for MYR and GLs to diffuse out and bind to each other [5]. Heating affects epithiospecifier proteins (ESP), MYR, and GL content. ESPs are responsible for the conversion of GLs to nitriles [1] and are less heat stable than MYR. Their inactivation allows for the preferential formation of ITCs [21,22]. Any type of prolonged high temperature heating, however, may cause MYR denaturation $[5,19,21]$ and GL thermal degradation [21]. Freeze drying has been shown to retain MYR and GLs [3]. Prior to freeze drying, microwave cooking at adequate power inputs, inactivates ESP while preserving MYR activity which increases bioaccessibility.

SR formation occurs mostly in two organs: the mouth during mastication and in the gut by the microbiota. Research shows that there are differences between individuals in oral processing of foods [23]. Sarvan et al. [20] investigated, in-vivo, the effect of steaming and chewing time on the bioaccessibility of SR and SR-Nitrile, the GR breakdown products 
after chewing. Results showed that longer chewing times of broccoli with active MYR led to more GR hydrolysis. Compared to raw broccoli, or broccoli steamed for shorter periods, chewing broccoli steamed for $2 \mathrm{~min}$ provided the highest amount of SR. Broccoli steamed for 3 min provided the least amount of SR [20]. The effect of chewing on bioavailability was demonstrated by Shapiro et al. [24] who measured the difference in the amount of ITC metabolites excreted from urine when broccoli sprouts were swallowed whole or chewed thoroughly. They found that chewing increased the amount of urine metabolites by 1.5 times.

In broccoli products with inactivated MYR due to prolonged heating, the gut conversion processes of GR to SR and other degradation products become important. The capability of an individual's gut microbiome to convert GR to SR will depend on the types of microbes, their quantities, and how effective their different mechanisms for bioconversion are. Gut bacteria convert GLs to other compounds besides ITCs (Figure 1). Saha et al. [6] used a batch fermentation model with human gut bacteria to demonstrate that gut bacteria is capable of converting GR to SR, SR-nitrile, erucin, and erucin-nitrile. They also showed that the formation of erucin is preceded by the microbial conversion of GR to glucoerucin [6]. Consequently, the bioconversion of GL to non-ITC breakdown products reduces the bioavailability of ITCs.

Capturing the essence of the physiological processes for SR mathematically so that its biological effect can be simulated and predicted, is known as physiological-based modelling. This is an approach that considers the physiological basis of a bioactive compound's interaction with the human body before mathematical concepts are applied. Physiological-based models vary in terms of the number of physiological aspects (i.e., biological mechanisms, organs) considered. Some models only look at the gastrointestinal tract while others consider the whole body [25].

Various types of compartmental model have been described of which the most basic is the compartmental absorption and transit (CAT) model. In the CAT model, the small intestine is divided into a series of compartments and assumes linear transfer kinetics, passive absorption kinetics and well mixed compartments with uniform concentration $[26,27]$. The transit and absorption of a drug or food component is depicted by the following equation,

$$
\frac{d M_{n}}{d t}=K_{t} M_{n-1}-K_{t} M_{n}-K_{a} M_{n}, n=1,2, \ldots 7
$$

where $n$ is the number of compartments, $M$ is the amount or concentration of the component in the $n$th compartment, $K_{t}$ is the transit rate constant between compartments, and $K_{a}$ is the absorption rate constant of the component into the blood.

Based on the CAT model, the advanced compartmental absorption and transit (ACAT) model was developed to include more details. The ACAT compartmentalizes the stomach and large intestine so that gastric emptying and absorption from the large intestine can be considered. In addition to linear kinetics and passive absorption, the model considers non-linear kinetics due to protein binding, liver metabolism, or active transport and physiochemical factors such as particle size, solubility, density, and permeability [28].

Most physiological-based modeling research available are for pharmaceutical drugs. There are few studies that are related to food components and food products, and even fewer studies for modeling broccoli compounds. Punt et al. $[29,30]$ made whole body eight-compartment models to predict the bioactivation and detoxification of herb estragole in humans and rats. Le Feunteun et al. [31] made a five-compartment model that focused on the digestion of mini-pigs to study the effect of product matrices on the digestion of milk proteins. Strathe et al. [32] also made a model with four main compartments and 38 sub-compartments to study the digestion and absorption of macro-nutrients in growing pigs. Moxon et al. [33] made a two-compartment model to investigate the effect of gastric emptying, luminal viscosity and hydrolysis rate on the rate of glucose absorption.

At the time of writing this article one study was found about the physiological-based modeling of SR from broccoli. Li et al. [34] investigated the kinetics and distribution of 
sulforaphane in the tissues of mice using a physiological-based model, where the whole body was divided into eight compartments. The mice ingested fresh, steamed, and MYR treated steamed broccoli sprout powders. The difference in kinetics and distribution in the tissues between the three different products were compared. The model did not include SR absorption mechanisms, and it did not include GR to SR conversion processes in the mouth, via myrosinase, and in the gut, via microbes. Also, the study did not extrapolate their results from mice to humans. The conversion of GR in the gut and mouth are important process that affect bioavailability. Therefore, a physiological-based model that considers these processes is needed.

The objective of this study was to make a physiological-based model that describes the kinetics and bioavailability of isothiocyanates from broccoli and to evaluate how the derived parameters are impacted by inter-individual variation. The model is validated against urine excretion sulforaphane data from a previous 2014 Wageningen University in-vivo research study by Oliviero et al. [35]. In this study, the effect of residual myrosinase activity on ITC formation, bioavailability, and excretion kinetics was investigated after 15 test subjects (apparently healthy human volunteers, aged 26-50 years, body mass index $21 \pm 2 \mathrm{~kg} / \mathrm{m}^{2}$, six men and nine women, 13 Caucasian, two Asian, and one Latin American), consumed five broccoli products with different levels of myrosinase activity obtained by different levels of microwave heating.

\section{Materials and Methods}

\subsection{Pre-Modeling Data Processing}

Participant raw data (measured SR urine conjugate excretion rates) from the Oliviero et al. [35] study was preprocessed for use in Matlab. The data were the time (minutes) and sulforaphane (SR) excretion rate $(\mu \mathrm{mol} / \mathrm{min})$. The technique used to measure SR urine conjugates, solid phase extraction-HPLC-MS/MS [35-37], is associated with experimental error that was quantified by Vermeulen et al. [37]. The relative standard deviation 12, 6 , $3 \%$ for $1.04,10.5$, and $313 \mu \mathrm{M} \mathrm{SR}$, respectively, in urine, was used to derive the following exponential equation that helped estimate the experimental error of each data point.

$$
y=0.11505 x^{-0.24}
$$

The relative error ratio is $\mathrm{y}$, and the concentration of SR is $x$. The experimental errors were plotted as error bars on the data points for the model fittings.

\subsection{Model Description and Assumptions}

The model (Figure 2) focuses on the processes involved in the gastro-intestinal transit of glucoraphanin (GR) and sulforaphane (SR). Similar to an advanced compartmental absorption and transit (ACAT) model, it includes the stomach, seven compartments of the small intestine [28], the colon, and a blood compartment for systemic circulation. Unlike an ACAT, the colon, was divided into seven compartments, the stomach into two compartments [31]. A mouth compartment, which is typically not in physiological-based models, was included. As a result of this the full model contains 18 compartments.

The products consumed in the intervention study were portions of $5 \mathrm{~g}$ of each broccoli product with $90 \mathrm{~mL}$ of water at $40^{\circ} \mathrm{C}$, and with $30 \mathrm{~g}$ of raisin bun and water ad libitum. During mastication, myrosinase (MYR) and GRs released from the cell structures react to form an O-sulfated thiohydroximate intermediate, which then immediately converts to SR or SR-nitrile. The amount of the intermediate that is converted to SR versus SR-nitrile is a ratio that is subject to change depending on the individual's chewing pattern and broccoli product. In the mouth, it is assumed that SR-nitrile is the only non-ITC compound formed. Mastication time (30 s) and saliva flow rates $(0.033 \mathrm{~mL} / \mathrm{s})$ [38] are assumed to be the same for all participants. The volume of the mouth compartment is the product plus the saliva excretions, $0.096 \mathrm{~L}$. 


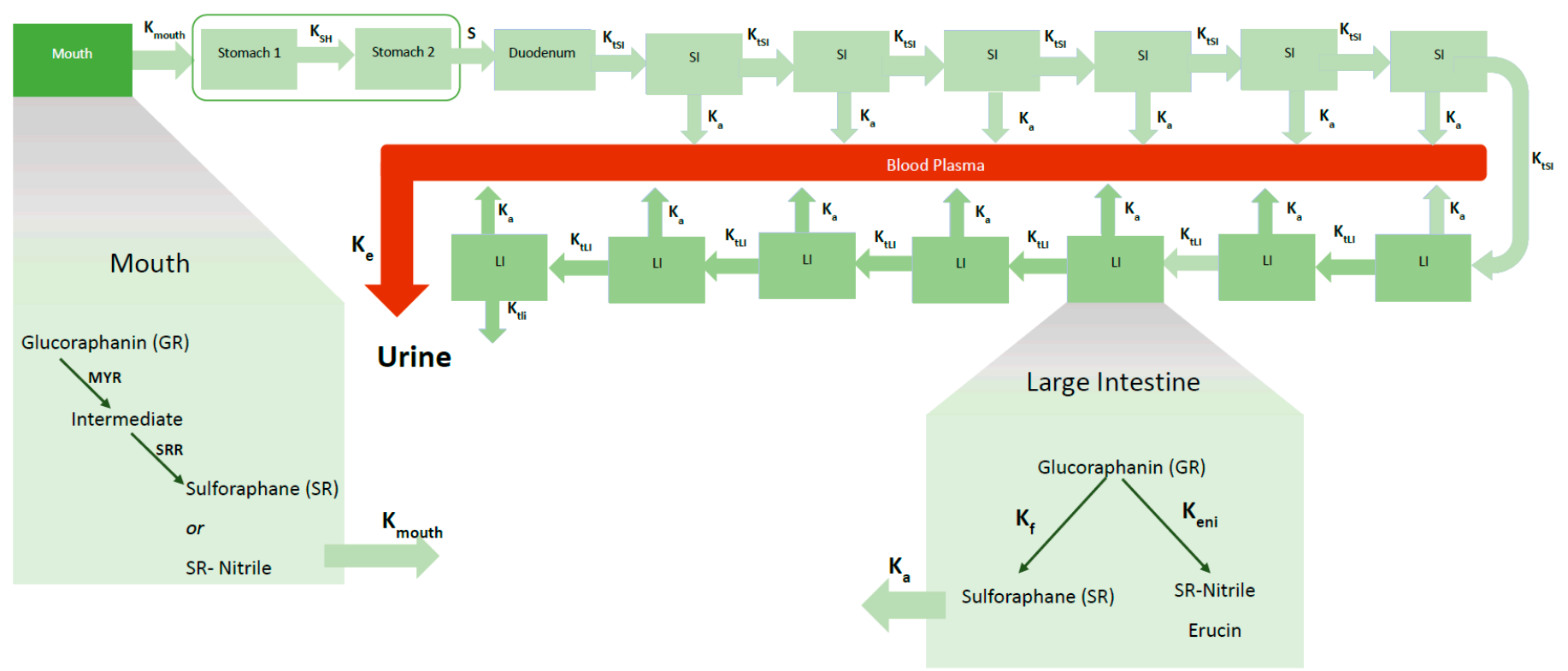

Figure 2. Schematic diagram of model with one mouth compartment, two stomach compartments, seven small intestine (SI) compartments and seven large intestine (LI) compartments, and one blood compartment. The conversion of glucoraphanin (GR) to sulforaphane (SR) and SR-nitrile and erucin in the mouth and large intestine is depicted. Shown are the transit rate constants between the mouth and stomach $\left(\mathrm{K}_{\text {mouth }}\right)$, between the two stomach compartments $\left(\mathrm{K}_{\mathrm{SH}}\right)$, between the stomach and duodenum $(\mathrm{S})$, between the small intestines $\left(\mathrm{K}_{\mathrm{tSI}}\right)$, between the large intestines $\left(\mathrm{K}_{\mathrm{tLI}}\right)$. The absorption of SR from the SI and LI into the blood is represented by the absorption rate constant $\left(\mathrm{K}_{\mathrm{a}}\right)$. Elimination of SR and SR-conjugates from the blood to urine is represented by the rate constant, $\mathrm{K}_{\mathrm{e}}$. During mastication, GR is converted to an intermediate by myrosinase (MYR) and the subsequently converted to SR or SR-nitrile based on a conversion ratio (SRR). The gut microbial conversion of GR to SR and SR-nitrile/erucin is represented by the rate constants $\mathrm{K}_{\mathrm{f}}$ and $\mathrm{K}_{\mathrm{eni}}$, respectively.

Swallowing transfers the bolus to the stomach. The first stomach compartment accounts for the disintegration of food particles that are too big to pass through the pyloric sphincter valve leading into the small intestine. Food broken down sufficiently, and mixed with gastric fluids in the first compartment, is moved to the second stomach compartment where it mixes with more gastric juices before emptying into the duodenum. Gastric emptying of solid foods has been described as having a biphasic nature due to the time required for enzymatic and mechanical disintegration before emptying into the intestines [39]. Any MYR is assumed to be deactivated irreversibly in the stomach due to the low $\mathrm{pH}$ of the gastric fluids [19,40]. It is also assumed that GLs and ITCs are not absorbed in the stomach. Transit from second stomach compartment to the duodenum depends on the stomach emptying time $(30 \mathrm{~min}$ ) which is assumed to be the same for all participants since the size of the meal is the same. Based on the meal size, the volume of both stomach compartments together is $0.2 \mathrm{~L}$, of which $0.05 \mathrm{~L}$ is the volume of the first stomach compartment (Table 1).

The chyme is mixed with duodenal secretions in this first compartment of the small intestine (SI). Due to the differences in the intestinal lining of duodenum (less villi/area for absorption) compared to the rest of the small intestine, less nutrients are absorbed in the duodenum; for simplicity, it is assumed there is no ITC absorption. In the remaining six SI compartments, SR is absorbed into the blood as both GR and SR are transferred from one compartment to the next.

The large intestine is divided into seven compartments where the following processes takes place: formation of SR, nitriles, and erucin by gut bacteria, absorption of SR into the blood, and transit of compounds from one compartment to the next. It is assumed that GRs are not absorbed from both the small and large intestines. Movement of chyme in the intestines are in the forward (towards the rectum) direction. Backward movements are 
known to occur and are represented by the fact that the compartments are assumed to be well mixed.

ITC is absorbed into the blood plasma, which is represented by one compartment that is presumed to be the same volume between all participants $(5 \mathrm{~L})$. Absorption of ITCs across the intestinal wall occurs passively by diffusion and is described according to Fick's Law of Diffusion [41]. ITC metabolites are eliminated from systemic blood circulation via glomerular filtration. No other elimination processes (sweat, defecation, respiration) are considered.

All compartment volumes (Table 1) are assumed to stay constant and the concentration of compounds (GR and SR) per compartment is uniform.

Table 1. Parameters values used in the model for the broccoli products, oral GR conversion processes, gastro-intestinal processes, gut GR conversion processes. Parameter values for the broccoli products $\mathrm{MYR}_{\mathrm{K}} \mathrm{Cgl}_{0}$ (initial glucosinolate concentration), and $\mathrm{ITC}_{0}$ (initial sulforaphane concentration) are separated by product (HighBP, HighBF, MedBF, LowBF, NoBF, each of these products have different MYR content due to different levels of microwave heating). Parameters designated as 'Estimated' were used in model fittings.

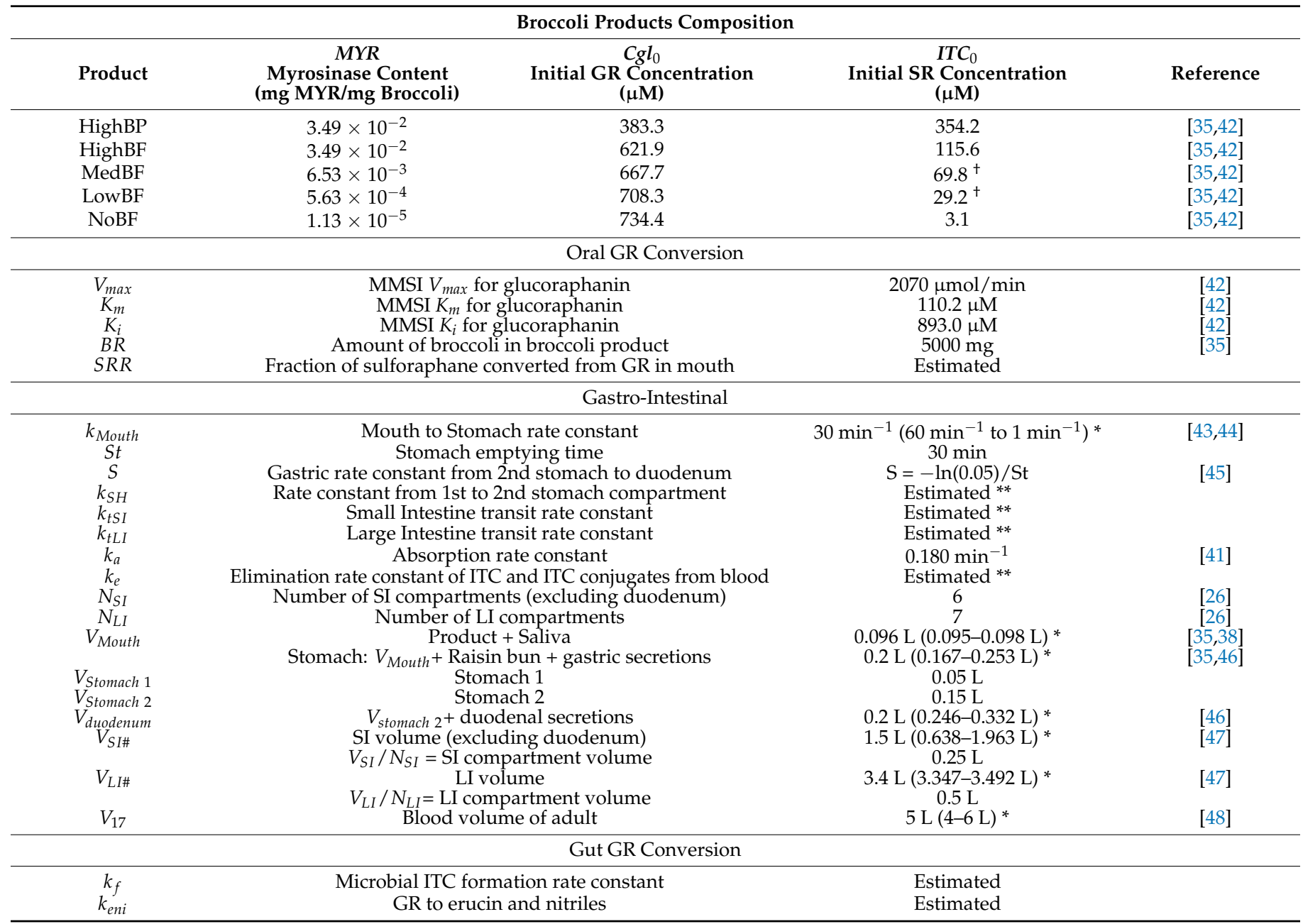

* Ranges for the parameters were determined based on literature. ** These values were estimated for each individual participant based on the model fit of the experimental values. ${ }^{+} \mathrm{ITC}_{0}$ values used in final fittings for MedBF and LowBF were approximately 3.4 and $9.1 \%$, respectively, of their values in this table due to poor fit results using the original values.

\subsection{Compartmental Mathematics}

The enzymatic reaction of GL and MYR to form the O-sulfated thiohydroximate intermediate in the mouth is characterized by a Michaelis-Menten equation that accounts for enzyme inhibition. The intermediate instantly reacts to form ITC or ITC-nitrile, there- 
fore the change in GL concentration is negatively proportional to the Michaelis-Menten equation.

$$
\frac{d C_{G L}}{d t}=-\left(\frac{V_{\max } \times M Y R \times B R \times C_{G L \text { Mouth }}}{K_{m}+C_{G L \text { Mouth }}+\frac{C_{G L \text { Mouth }}{ }^{2}}{K_{i}}}\right)
$$

$M Y R$ is the estimated mg of myrosinase per one $\mathrm{mg}$ of dried broccoli. Details on how $M Y R$ was estimated is found in Appendix A Part I. BR is the amount of dried broccoli (5 g) consumed by the participants. The maximum rate, $V_{\max }\left(\mu \mathrm{M} / \mathrm{min}^{*} \mathrm{mg} M Y R\right)$, the Michaelis constant, $K_{m}(\mu \mathrm{M})$, and the inhibition constant, $K_{i}(\mu \mathrm{M})$ were derived using glucoraphanin data from Roman et al.'s [42] MYR kinetic study. Details on the derivation of these variables can be seen in Appendix A Part II.

The amounts of ITC and nitriles formed is expressed as a fraction of the amount of intermediate (Equations (4) and (5)).

$$
\frac{d C_{I T C} \text { Mouth }}{d t}=S R R \times \frac{d C_{G L}}{d t}
$$

and

$$
\frac{d C_{\text {Nitrile Mouth }}}{d t}=(1-S R R) \times \frac{d C_{G L}}{d t}
$$

$S R R$ is the fraction of hydrolyzed GR converted to $S R$ in the mouth. The remaining, 1 - $S R R$, is converted to nitriles.

Transfer of ITCs and GLs out of the mouth, as well as into and out of the stomach and intestinal compartments are first order rate reactions (Equations (6) and (7)).

$$
\frac{d C_{I T C} i}{d t}=k_{\text {transfer (i-1 to } i)} \times \frac{V_{i-1}}{V_{i}} \times C_{I T C} i-1
$$

and

$$
\frac{d C_{G L i}}{d t}=k_{\text {transfer (i-1 to } i)} \times \frac{V_{i-1}}{V_{i}} \times C_{G L i-1}
$$

The rate constants for transfer from the mouth, $k_{\text {mouth }}$, for the stomach compartments, $k_{S H}$ and $S$, and intestinal compartments, $k_{t s i}$ and $k_{t l i}$, are the inverses of the residence time of each compartment (Table 1). Due to differences in some compartment volumes (V), volume ratios are considered.

The gut formation of ITCs, nitriles, and erucin are also represented by the following first order rate reactions,

$$
\begin{gathered}
\frac{d C_{I T C}}{d t}=k_{f} \times C_{G L} \\
\frac{d C_{\text {Nitrile \& Erucin }}}{d t}=k_{\text {eni }} \times C_{G L}
\end{gathered}
$$

where $k_{f}$ is the rate constant of formation for ITC, and $k_{e n i}$ is the rate constant of formation for erucin and nitrile. The change in GL concentration in the gut is proportional to the formation of ITC, nitrile, and erucin.

$$
\frac{d C_{G L}}{d t}=-\left(k_{f} \times C_{G L}\right)-\left(k_{e n i} \times C_{G L}\right)
$$

Absorption into the blood is defined by the following equation,

$$
\frac{d C_{I T C}}{d t}=k_{a} \times C_{I T C}
$$


where $k_{a}$, is the rate of absorption (passive diffusion) from the intestines and it is proportional to the effective permeability $\left(P_{\text {eff }}\right)$ of sulforaphane and inversely proportional to the radius, $R$, of the intestines [49].

$$
k_{a}=\frac{2 P_{e f f}}{R}
$$

Each compartment is defined by mass balanced differential equations that contain the processes just described. For example, the full ITC and GL differential equations for the seventh small intestine compartment and first large intestine compartment are shown, Equations (13)-(16),

Seventh small intestine compartment:

$$
\begin{aligned}
& \frac{d C_{I T C S I 7}}{d t}=\frac{V_{S I 6}}{V_{S I 7}} \times\left(k_{t S I} \times C_{I T C ~ S I 6}\right) \quad-\left(k_{t S I} \times C_{I T C ~ S I 7}\right) \quad-\left(k_{a} \times C_{I T C ~ S I 7}\right) \\
& \text { ITC In ITC Out ITC Absorption } \\
& \frac{d C_{G L S I 7}}{d t}=\frac{V_{S I 6}}{V_{S I 7}} \times\left(k_{t S I} \times C_{G L S I 6}\right) \quad-\left(k_{t S I} \times C_{G L S I 7}\right) \\
& \text { GL In GL Out }
\end{aligned}
$$

First large intestine compartment:

$$
\begin{aligned}
& \begin{array}{ccccc}
\frac{d C_{I T C L 11}}{d t}=\frac{V_{S I 7}}{V_{L I 1}} & \times\left(k_{t S I} \times C_{I T C S I 7}\right) & +\left(k_{f} \times C_{G L L I 1}\right) & -\left(k_{t L I} \times C_{I T C L I 1}\right) & -\left(k_{a} \times C_{I T C ~ L I 1}\right) \\
& \text { ITC In } & \text { ITC Formation } & \text { ITC Out } & \text { ITC Out }
\end{array} \\
& \frac{d C_{G L L I 1}}{d t}=\frac{V_{S I 7}}{V_{L 11}} \times\left(k_{t S I} \times C_{G L S I 7}\right) \quad-\left(k_{f} \times C_{G L L I 1}\right) \quad-\left(k_{t L I} \times C_{G L L I 1}\right) \quad-\left(k_{e n i} \times C_{G L L I 1}\right) \\
& \text { GL In ITC Formation GL Out Erucin/Nitrile Formation }
\end{aligned}
$$

Full list of differential equations for all compartments are in the Supplementary Files.

\subsection{Simulink Model}

The mathematical equations used to represent the different compartmental processes were translated to a block diagram on Matlab's Simulink application (Matlab R2020a). Code scripts written on the MATLAB (MathWorks) interface integrated with the Simulink block diagram model to run sensitivity analyses and to perform fitting on the five different broccoli products.

\subsection{Matlab Coding and Fittings}

Sensitivity Analysis. Sensitivity analysis was performed to see the effect of changing parameter values on the model output. A parameter was changed within literature determined ranges while other parameters were kept constant. The analysis was performed for the different broccoli products, NoBF, LowBF, MedBF, HighBF, and HighBP.

Model Fittings. After the sensitivity analysis, parameters with the most influence on the simulation output, were used for fitting the model to each participant's data set. The fitting was done using a Trust-Region-Reflective Least Squares algorithm from the least squares data fitting solver of Matlab's Optimization Toolbox. The simulation period was $1600 \mathrm{~min}(26 \mathrm{~h})$. Values of parameters used for fitting are in Table 1 . This fitting procedure yielded parameter estimates that gave the best fit between the model simulations and the experimental data of the intervention study.

\subsection{Statistical and Data Analysis}

Confidence Intervals for each parameter estimate were determined at $90 \%$ confidence using Matlab's non-linear parameter confidence interval function. This function also provided covariance matrices that were used to calculate the correlation coefficients.

Using Matlab's trapezoidal numerical integration function, the cumulative SR excreted per participant for the experimental and predicted data sets were calculated.

Full codes are provided in the supplementary files. 


\section{Results}

\subsection{Sensitivity Analysis and Parameters Selection}

The model's sensitivity towards twelve parameters was tested. Based on the analysis, three parameters were used in model fittings for HighBP and HighBF, seven for Med and Low BF, and five for NoBF (Table 2).

Table 2. Summary of parameters that influenced the simulation outputs for each broccoli product during the sensitivity analysis. Parameters with a check mark $(\checkmark)$ were used for model fittings; parameters with an $\mathrm{O}$, influenced simulation output but were not used in model fittings; parameters with an $x$ did not affect output during the sensitivity analysis and were excluded from fitting. Three parameters were used to fit HighBP and HighBF, seven for MedBF and LowBF, and five for NoBF.

\begin{tabular}{|c|c|c|c|c|c|c|c|c|c|c|c|c|}
\hline & $\mathbf{k}_{\mathrm{SH}}$ & SRR & $\mathbf{k}_{\mathrm{f}}$ & $\mathbf{k}_{\mathbf{e}}$ & $\mathbf{k}_{\mathrm{tSI}}$ & $k_{\mathrm{tLI}}$ & $\mathbf{k}_{\text {eni }}$ & $\mathrm{Cgl}_{0}$ & ITC $_{0}$ & MYR & $\mathbf{k}_{\mathbf{a}}$ & St \\
\hline HighBP & $\checkmark$ & $\checkmark$ & $x$ & $\mathrm{o}$ & $\checkmark$ & $x$ & $x$ & $\mathrm{O}$ & $\mathrm{o}$ & $\mathrm{o}$ & $x$ & $x$ \\
\hline HighBF & $\checkmark$ & $\checkmark$ & $x$ & o & $\checkmark$ & $x$ & $x$ & o & $\mathrm{O}$ & o & $x$ & $x$ \\
\hline MedBF & $\checkmark$ & $\checkmark$ & $\checkmark$ & $\checkmark$ & $\checkmark$ & $\checkmark$ & $\checkmark$ & o & o & $\mathrm{O}$ & $x$ & $x$ \\
\hline LowBF & $\checkmark$ & $\checkmark$ & $\checkmark$ & $\checkmark$ & $\checkmark$ & $\checkmark$ & $\checkmark$ & $\mathrm{O}$ & $\mathrm{O}$ & $\mathrm{O}$ & $x$ & $x$ \\
\hline NoBF & $\checkmark$ & $x$ & $\checkmark$ & $x$ & $\checkmark$ & $\checkmark$ & $\checkmark$ & o & $\mathrm{O}$ & $\mathrm{O}$ & $x$ & $x$ \\
\hline
\end{tabular}

Parameters that did not affect model output were excluded. Gastric emptying time (St), and the rate constant of absorption $\left(\mathrm{k}_{\mathrm{a}}\right)$, were excluded from all model fittings because they had insignificant effects on the output (example in Figure 3A,B). As expected, myrosinase content (MYR), initial GR concentration $\left(\mathrm{Cgl}_{0}\right)$, initial SR concentration $\left(\mathrm{ITC}_{0}\right)$, and the ratio of GR converted to SR in the mouth (SRR), caused a direct and proportional upward shift to the HighBP, HighBF, MedBF, and LowBF simulation outputs (example in Figure 3C,D). The MYR and ITC $_{0}$ contents were low for NoBF, therefore, of the broccoli product related parameters, only $\mathrm{Cgl}_{0}$ affected the output. Furthermore, the conversion ratio of GR to SR in the mouth (SRR), which depends on myrosinase content, did not affect the output of NoBF during the sensitivity analysis since myrosinase was inactive (Figure 3J). The first stomach rate constant $\left(\mathrm{K}_{\mathrm{SH}}\right)$, small intestine transit rate constant $\left(\mathrm{k}_{\mathrm{tSI}}\right)$ and SR elimination from the blood $\left(\mathrm{k}_{\mathrm{e}}\right)$, also caused proportional upward shifts but a narrowing of the curves was observed (example Figure $3 \mathrm{~L}$ ). The gut parameters, ITC formation $\left(\mathrm{k}_{\mathrm{f}}\right)$ and erucin and nitrile formation $\left(k_{\text {eni }}\right)$ rate constants, had opposite effects on outputs. Increases in $\mathrm{k}_{\text {eni }}$ resulted in downward shifts and narrowing of the output curves (Figure $3 \mathrm{H}$ ), while the curves shifted upwards for $\mathrm{k}_{\mathrm{f}}$ (Figure $3 \mathrm{G}$ ). Increasing gut transit rate constant $\left(\mathrm{k}_{\mathrm{tLI}}\right)$, decreased the size of the second peak for MedBF and LowBF, and the single peak for NoBF (example in Figure $3 \mathrm{~F}$ ). Changes in $\mathrm{k}_{\mathrm{tLI}}$ did not affect outputs of HighBP and HighBF products (Figure 3E).

\subsection{Model Fittings}

The model was successfully fit to the data of each participant and for each product. Figure 4 shows the model fits for five of the participants and for all five broccoli products. 75 fittings were possible ( 15 participants times five products) but only 72 fitting were performed. Three data sets were excluded due to lack of data. While four data sets had to be preprocessed before fitting.

Few data sets had poor fits. Participant $m$, for the MedBF product, was underfitted while participants $q$, MedBF, and $g$, LowBF, were overfitted (Figures 4 and S1: Model Fittings Results for All Participants in the Supplementary Files). 

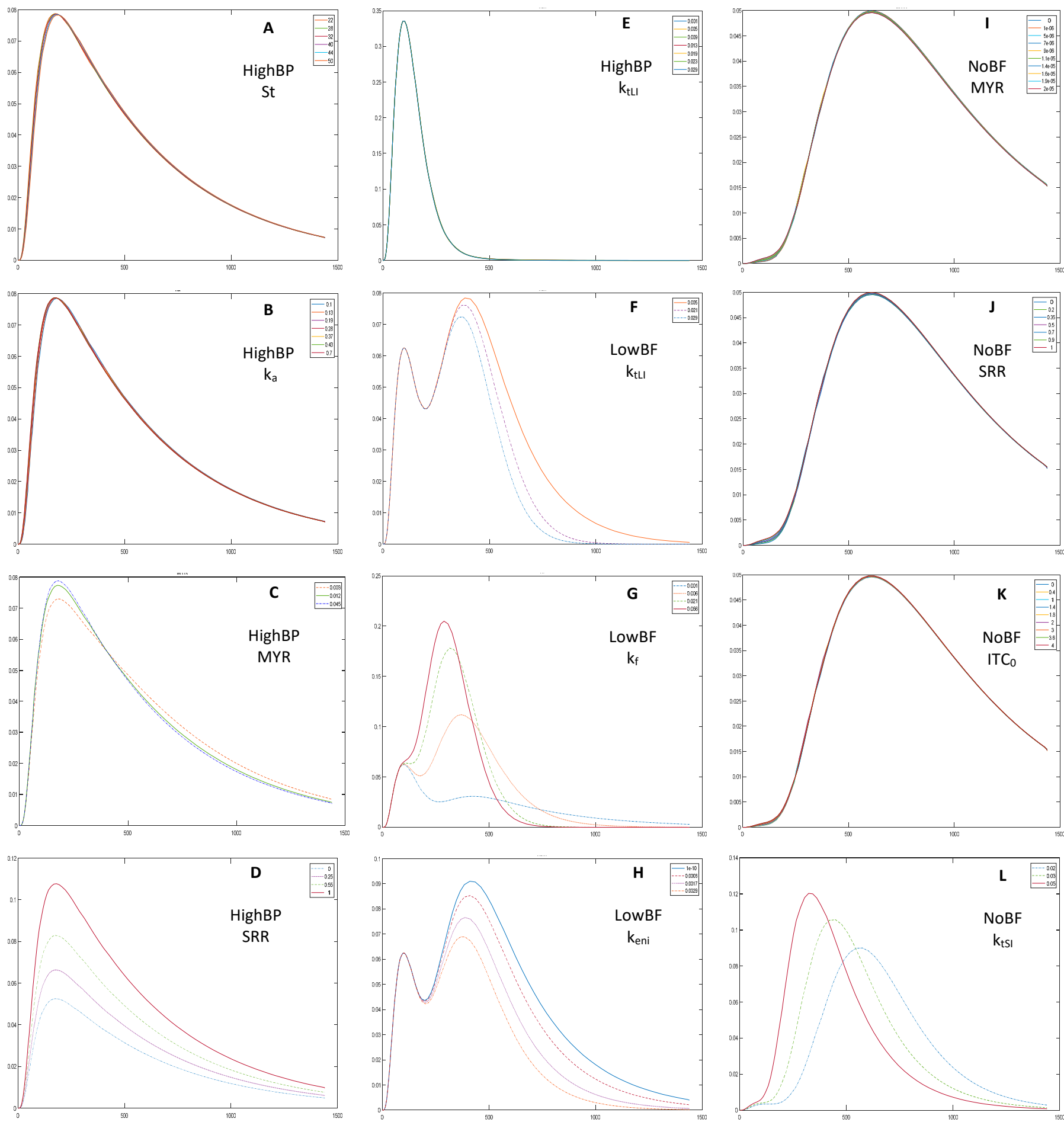

Figure 3. HighBP sensitivity analysis for (A) gastric emptying time, $\mathrm{St}$; (B) the rate constant of absorption, $\mathrm{k}_{\mathrm{a}}$; (C) myrosinase content, MYR; (D) the ratio of GR converted to SR in the mouth, SRR; (E) large intestine transit rate constant, $\mathrm{k}_{\mathrm{tLI}}$. LowBF sensitivity analysis for $(\mathbf{F})$ large intestine transit rate constant, $\mathrm{k}_{\mathrm{tLI}} ;(\mathrm{G})$ ITC formation rate constant in the gut, $\mathrm{k}_{\mathrm{f}}$; and (H) erucin and nitrile formation rate constant in the gut, $\mathrm{k}_{\mathrm{eni}}$. NoBF sensitivity analysis for (I) myrosinase content, MYR; (J) the ratio of GR converted to SR in the mouth, SRR; (K) and initial ITC concentration (ITC 0 ) and (L) small intestine transit rate constant, $\mathrm{k}_{\mathrm{tSI}}$. The sensitivity analysis shows how the simulation output changes when all parameters are kept constant while one changes. 

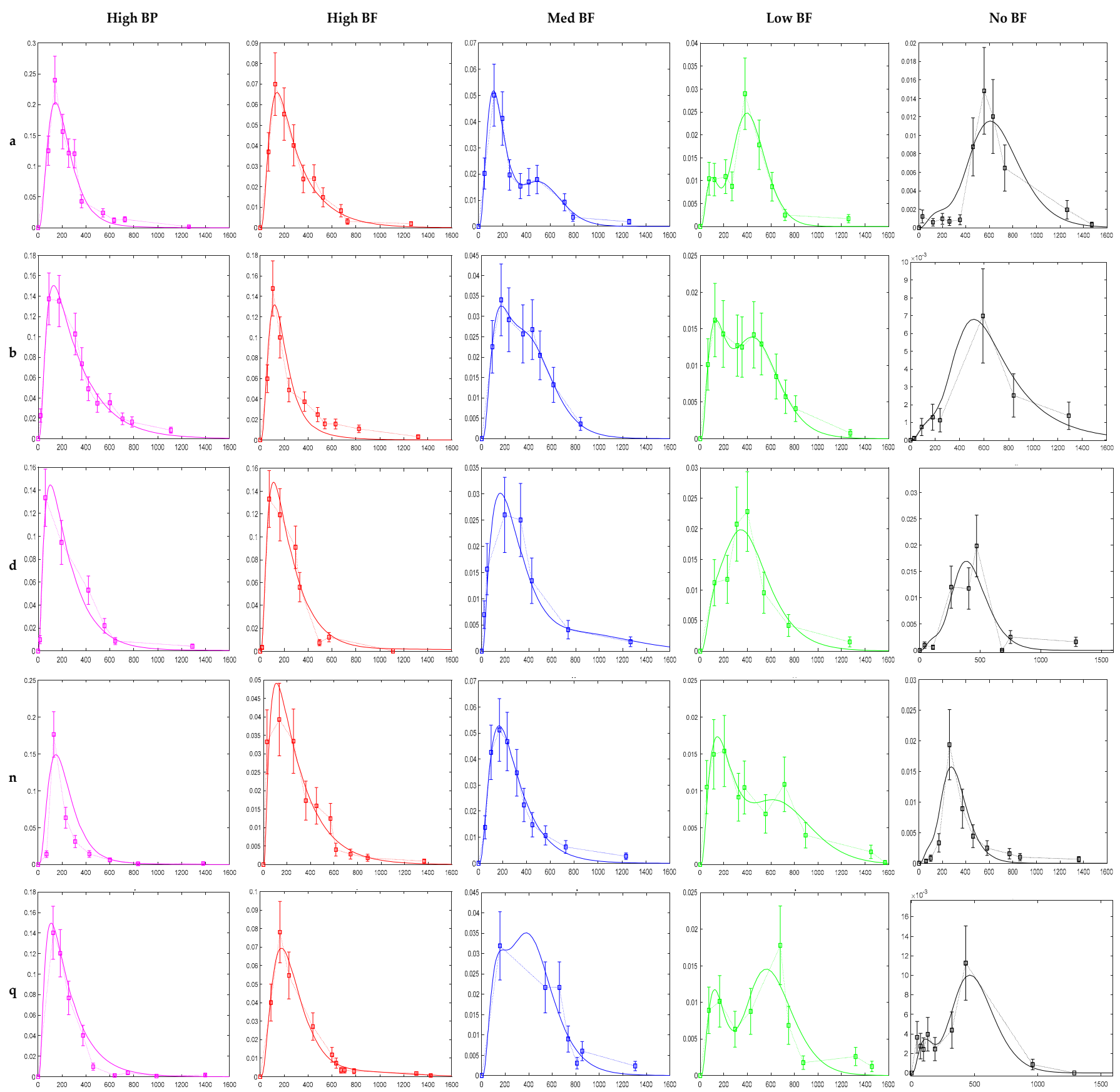

Figure 4. Model fittings for participants $a, b, d, n, q$. $X$ and $Y$ axis for each graph is, time (min) and sulforaphane conjugate excretion rate $(\mu \mathrm{mol} / \mathrm{min})$, respectively. Experimental data are the square bullets, and the solid lines are the model fits. Error bars represent potential experimental error from the analytical techniques used by Oliviero et al. to measure the amounts of ITC conjugates in urine. All participant model fittings are in Figure S1: Model Fittings Results for All Participants in the Supplementary Files.

\subsection{Bioavailability of Sulforaphane}

Bioavailability was calculated by dividing the cumulative amounts of SR by the amount of GR in the broccoli products. Cumulative amounts of SR for the experimental data and model data were determined using Matlab's trapezoid function to integrate. There were small differences between the predicted bioavailability and experimental bioavailability (Table 3). Average HighBP predictions were $2 \%$ larger than the calculated experimental bioavailability. The difference was $1 \%$ for MedBF, $0.9 \%$ for LowBF, and $0.1 \%$ for HighBF and NoBF. 
Table 3. Average sulforaphane (SR) bioavailability values \pm SD for the experimental data and model. There were minor differences between the experimental bioavailability and model bioavailability for each broccoli product type.

\begin{tabular}{cccc}
\hline \multicolumn{4}{c}{ Average SR Bioavailability (\%) } \\
\hline Experimental Data & Model & Difference \\
\hline HighBP & $63 \pm 0.2$ & $65 \pm 0.1$ & $2 \%$ \\
MedBF & $33 \pm 0.1$ & $33 \pm 0.1$ & $0.1 \%$ \\
LowBF & $25 \pm 0.1$ & $24 \pm 0.1$ & $1 \%$ \\
NoBF & $19 \pm 0.1$ & $18 \pm 0.1$ & $0.9 \%$ \\
\hline
\end{tabular}

\subsection{Mouth and Gut Parameter Estimations}

Tables 4-6 shows the distribution (boxplots) of mouth and gut parameter estimates for each product type. Interquartile ranges (IQR) for the parameter estimates varied widely. The distributions of most parameter estimates are positively skewed indicating that $50 \%$ of participants are less variable within the first two quartiles than the $50 \%$ of participants in quartile three and four.

Table 4. SRR estimation results (horizontal red bar: median, blue box second and third quartile, whiskers first and fourth quartiles).

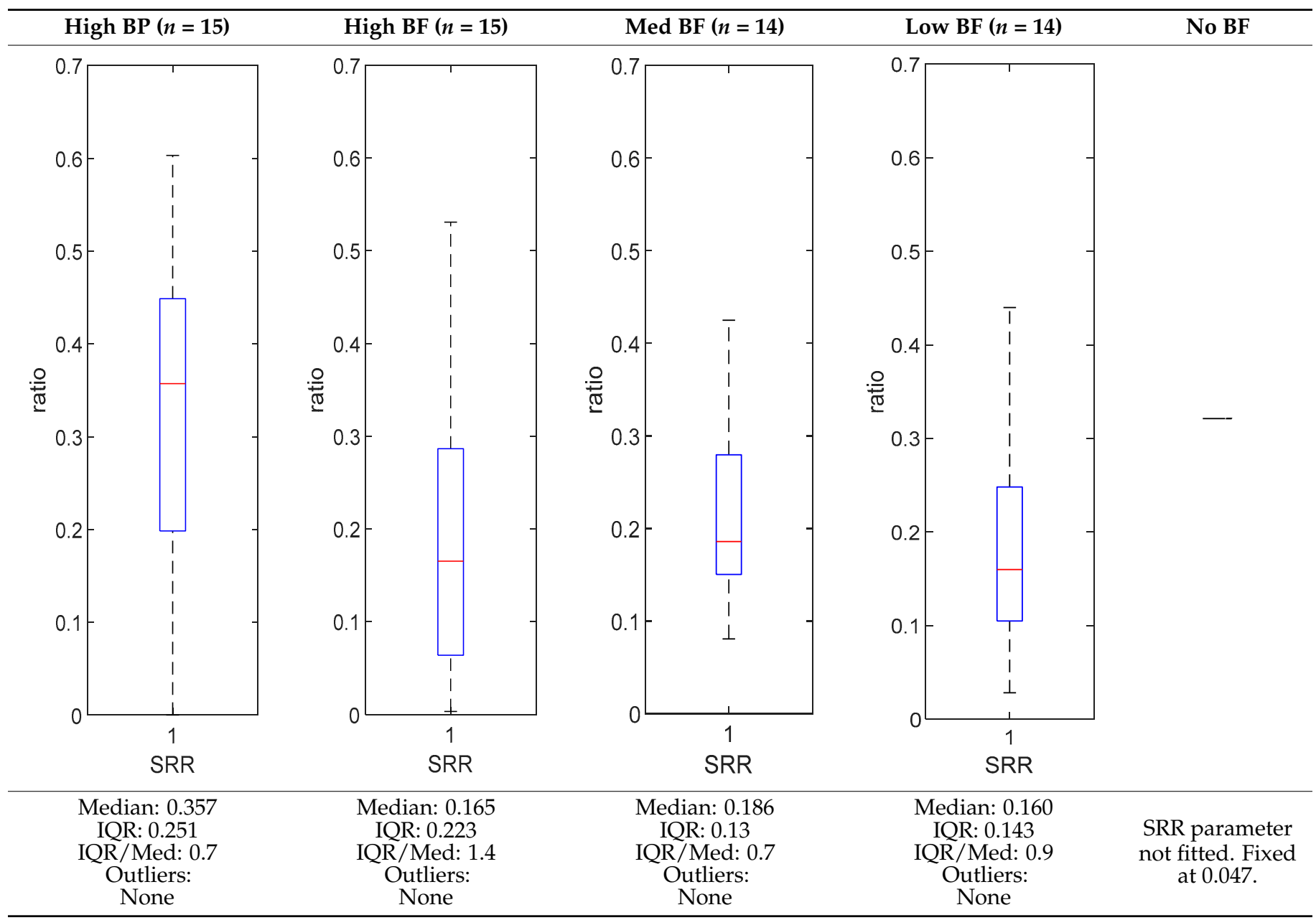


Table 5. $\mathrm{k}_{\mathrm{f}}$ estimation results (horizontal red bar: median, blue box second and third quartile, whiskers first and fourth quartiles, +: outliers).

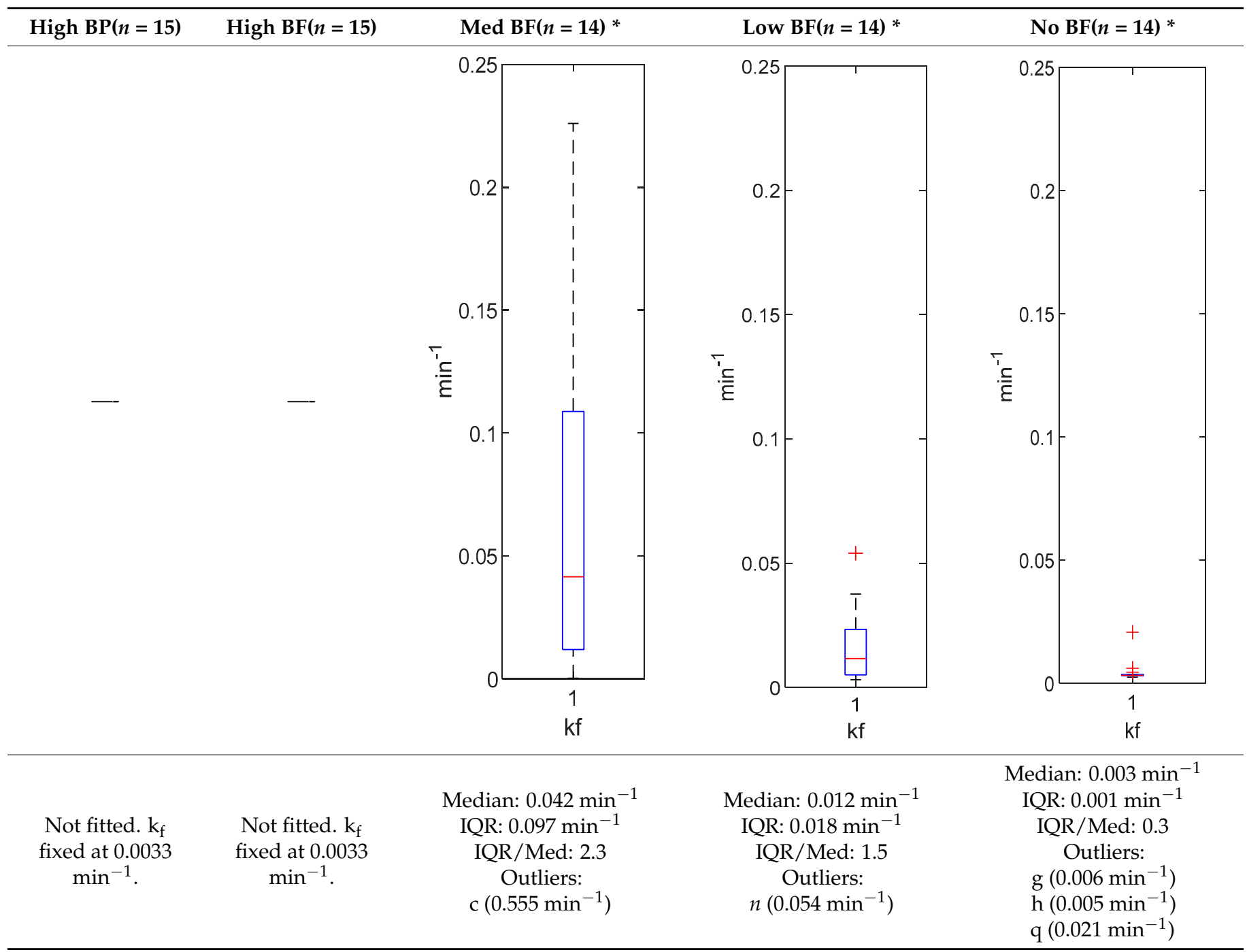

* Some or all outliers excluded for better visual presentation and comparison of boxplots. Outliers are values more than 1.5 times the IQR. See Supplementary Files for plotted outliers and for expanded view of the NoBF $\mathrm{k}_{\mathrm{f}}$ boxplot.

SRR, the ratio of GR that gets converted to SR in the mouth, was estimated for each participant who consumed the HighBP, HighBF, Med and Low BF products (Table 4). SRR was not fitted for the NoBF product since the amount of MYR is very low. Therefore, any GR converted to SR in the mouth is insignificant for the NoBF product. The medians for HighBF, MedBF, and LowBF mean that half of the participants converted less than 19\% GR to SR in the mouth. HighBP distribution, on the other hand, is negatively skewed with half the participants converting 35 to $60 \%$ of GR (median $=0.357$ ) to SR.

$\mathrm{K}_{\mathrm{f}}$ and $\mathrm{k}_{\mathrm{eni}}$ represent the rate of formation of sulforaphane and erucin and nitriles, respectively, by gut bacteria in the large intestine. These parameters were estimated for the MedBF, LowBF and NoBF products but not for the High myrosinase products. $\mathrm{K}_{\mathrm{f}}$ was fixed at $0.0033 \mathrm{~min}^{-1}$ and $\mathrm{k}_{\text {eni }}$ was fixed at $0.0015 \mathrm{~min}^{-1}$ for both products. All distributions are positively skewed indicating that at $50 \%$ of the participant metabolize GR to SR slower than $0.042 \mathrm{~min}^{-1}$ for MedBF, $0.012 \mathrm{~min}^{-1}$ for LowBF, and $0.003 \mathrm{~min}^{-1}$ for NoBF (Table 5); and they metabolize GR to erucin and nitrile slower than $0.017 \mathrm{~min}^{-1}$ for MedBF, $0.033 \mathrm{~min}^{-1}$ for LowBF, and $0.003 \mathrm{~min}^{-1}$ for NoBF (Table 6).

The results of other parameters are discussed in Appendix B. 
Table 6. $\mathrm{k}_{\mathrm{eni}}$ estimation results (horizontal red bar: median, blue box second and third quartile, whiskers first and fourth quartiles, +: outliers).

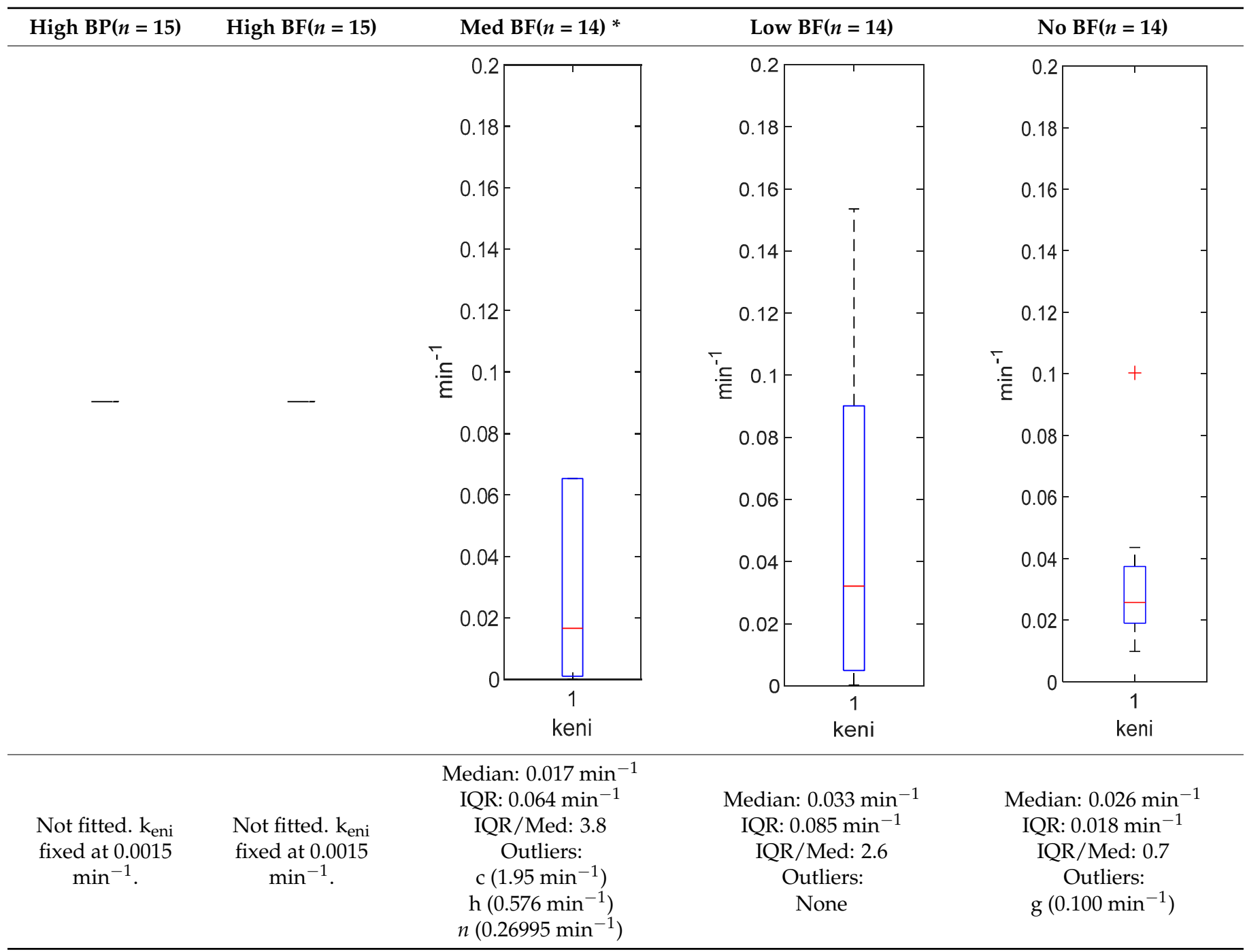

* Some or all outliers excluded for better visual presentation and comparison of boxplots. Outliers are values more than 1.5 times the IQR. See Supplementary Files for plotted outliers.

\subsection{Certainty of Parameter Estimates}

For each participant and broccoli product, $90 \%$ confidence intervals were calculated to determine the range of parameters that are likely to include the parameter estimates. The confidence intervals were very large and are therefore not a good measure of certainty in the parameter estimates. The percentage of participants that had intervals larger than $30 \%$ on either side of the estimated parameter, was $62 \%$ of participants for HighBP, $53 \%$ for HighBF, $96 \%$ for MedBF, $98 \%$ for LowBF, and 100\% for NoBF. The large confidence intervals were due to the limited data of each participant.

\subsection{Goodness of Fit}

A comparison between the experimental and the predicted values are shown in Figure 5. 

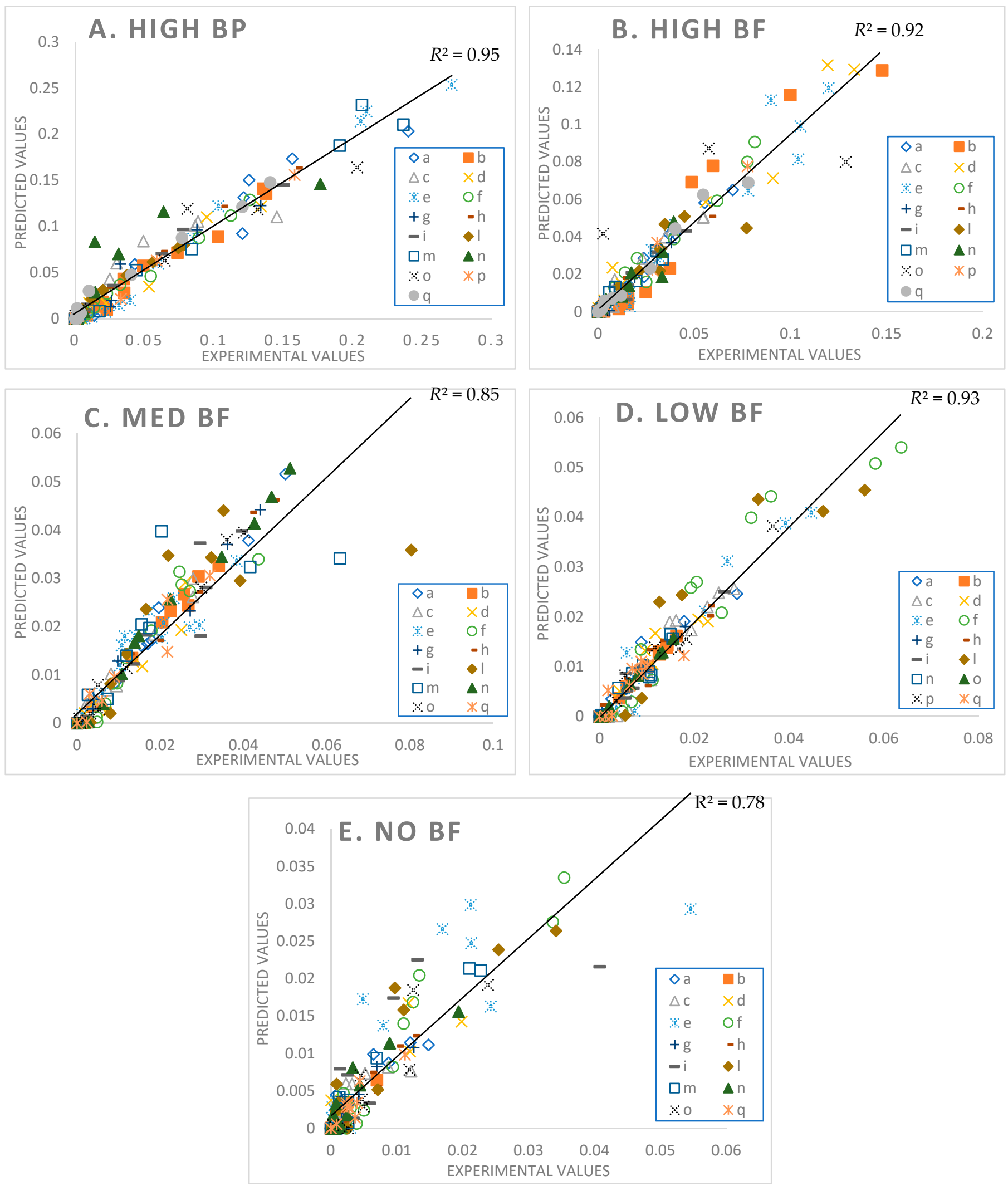

Figure 5. Parity plot of High MYR Broccoli Powder (A), High MYR Broccoli Florets (B), Medium MYR Broccoli Florets (C), Low MYR Broccoli Florets (D), and No MYR Broccoli Florets (E) with lumped participant data. Participants are designated by letters. 
The best fits are for the HighBP product $\left(R^{2}=0.95\right)$, followed by LowBF $\left(R^{2}=0.93\right)$, $\operatorname{HighBF}\left(R^{2}=0.92\right), \operatorname{MedBF}\left(R^{2}=0.85\right)$, and lastly $\operatorname{NoBF}\left(R^{2}=0.78\right)$. Most predicted values for NoBF are higher than their corresponding experimental values (Figure 5E). Of the five broccoli products NoBF was the most difficult to fit due to the narrow peaks and wider base for most of the excretion curves compared to the other products (see NoBF simulation results in Figure S1: Model Fittings Results for All Participants in the supplementary files.). A noticeable feature of the model for the HighBF, MedBF, LowBF, and NoBF products (Figures 5B-E and S1), is that the model solutions for some participants (e.g., participants $\mathrm{e}, 1, \mathrm{n}$ ) approached excretion rates of 0 faster than the data points. The fit on the tail end of the data points, as well as the general fits for NoBF, may be improved by updating the model to include future physiological information on GR gut conversions, ITC absorption, distribution, and elimination.

\section{Discussion}

\subsection{Sensitivity Analysis and Selection of Parameters}

Sensitivity analysis for each product type was conducted to understand how changing one parameter and keeping the other constant would affect the model simulation output. Parameters to be estimated in model fittings were selected based on the results of the sensitivity analysis and preliminary model fittings. Given the low amount of data (6-15 data points) per participant, this procedure helped reduce the number of parameters fitted to the most necessary, thereby increasing the degrees of freedom.

Parameters that affected model output but were excluded from final fittings were $\mathrm{k}_{\mathrm{e}}$, MYR, $\mathrm{Cgl}_{0}$, and $\mathrm{ITC}_{0}$. The model was sensitive to $\mathrm{k}_{\mathrm{e}}$ for the HighBP, HighBF, MedBF, and LowBF products. However, $\mathrm{k}_{\mathrm{e}}$ was not included in the fittings for HighBP and BF due to the poor model convergence. For all products, MYR and $\mathrm{Cgl}_{0}$ were fixed at the concentrations calculated from the Oliviero study (Table 1 and Matlab codes in the Supplementary Files). The initial concentration of SR (ITC ${ }_{0}$ ) calculated for HighBP, HighBF, and NoBF were kept at the values derived from the Oliviero study, while for MedBF and LowBF, ITC $_{0}$ was reduced in order to get a good fit (Table 1). The reduction in $\mathrm{ITC}_{0}$ may be explained by the high variability in the measured amounts of SR in the broccoli products. Oliviero et al. [35] measured SR in triplicates and the standard deviation for MedBF was $28.4 \%$ of the average, while for LowBF, it was $64.3 \%$; the standard deviations were the two highest out of the five products. $\mathrm{ITC}_{0}$ values used in the model were averages based on a sample size of three. Therefore, it is possible that most participants were consuming less SR initially. With the lower ITC $C_{0}$ values, the fittings for MedBF and LowBF had lower means squared error (MSE) values and better fits visually. As with $k_{e}$, the model function appeared to be stuck in a local minimum when ITC 0 was used at its original values. A better approach for future modeling might be to fit MYR, $\mathrm{Cgl}_{0}$, and $\mathrm{ITC}_{0}$ for all participants simultaneously. With the estimated MYR, $\mathrm{Cgl}_{0}$, and $\mathrm{ITC}_{0}$ kept constant, the remaining parameters sensitive to the model would be fitted.

More data are needed per participant, $>15$ data points, to get higher degrees of freedom. The number of data points per participant becomes important the greater the number of parameters being estimated. Obtaining a specified number of urine excretion data points from an intervention study is understandably not easy to achieve. Collecting blood samples during the intervention period in addition to urine samples would provide additional data for the model fittings that may improve parameter estimations as well as increase the number of parameters being estimated.

\subsection{Model Fittings}

The model succeeded in fitting the data of the various broccoli products well within the experimental error for most of the participants (Figures 4 and S1). It also described the myrosinase mediated conversion of GR in the mouth and the microbial conversion of GR in the gut well. The quick appearance (within 2-3 h after consumption) of the single excretion peaks for HighBP and HighBF products, represents excretion rates of SR that 
were initially consumed or formed in the mouth, and were absorbed in the small intestine. The NoBF product, which had an insignificant amount of myrosinase, had single peaks that appeared much later (7-8 h after consumption). The NoBF peaks represent excretion rates of SR that was formed by gut bacteria and absorbed only in the large intestine. MedBF and LowBF curves tend to have two peaks. The first peak representing absorption from the small intestine and the second peak from the large intestine. This excretion pattern due to differences in myrosinase content have been observed by other authors $[35,36,50,51]$.

\subsection{Bioavailability of Sulforaphane}

This compartment model is a good predictor of bioavailability. Other researchers observed that using a compartmental absorption and transit (CAT) model was better at predicting bioavailability than a single compartment model [52].

\subsection{Mouth and Gut Parameter Estimations}

The parameter estimates clearly show the variability between individuals in the amount of GR converted to SR during mastication and in their gut bacteria activity. The distributions (Tables 4-6) also vary across product categories. The median GR conversion ratio, SRR, is higher for HighBP compared to the HighBF, MedBF, and LowBF broccoli products. $50 \%$ of the HighBP participants have conversion ratios similar to what Sarvan et al. [20] found in their study for $0.5 \mathrm{~min}$ and $1 \mathrm{~min}$ cooked broccoli, where after chewing, $41 \%$ and $60 \%$ GR was converted to SR. The fact that the overall distribution for HighBP is shifted to higher values compared to HighBF demonstrates the importance of the product matrix. Although, both had the same myrosinase content, most of the participants could convert more GR to SR after consuming the powder. General differences in chewing patterns between individuals have been documented [23]. However, more specific studies on the effect of chewing patterns correlated to conversion GR ratios may provide insights into the variations observed between individuals in the parameter distributions.

The variation between products is significant for the gut parameters, $\mathrm{k}_{\mathrm{f}}$ and $\mathrm{k}_{\mathrm{eni}}$. The IQR for LowBF and NoBF were expected to be similar since most of the myrosianse was inactivated in both products. However, the NoBF IQR was significantly smaller, which implied that the participants in the Oliviero study had very similar gut bacteria or that their overall bacterial activity was similar. Unfortunately, data on the gut microbial population of the participants was not available to correlate to the parameter estimation results. It is well known that gut bacterial populations differ between individuals and populations [7,53-55]. Forty-seven bacterial species having been identified as having GL metabolizing activities in-vitro [9], but only a few have been investigated for their GL bioconversion mechanisms: Enterobacter cloacae [56], Lactobacillus agilis R16 and Escherichia coli VL8 [57], Bacteroides thetaiotaomicorn [58].

\section{Conclusions}

A physiological-based multicompartment digestion and absorption model, was developed to describe the kinetics and bioavailability of sulforaphane (SR) from broccoli, and to evaluate how the derived parameters are impacted by inter-individual variation. The model included reactions during digestion in the mouth and gut. It successfully fit participant data and was able to describe bioavailability of SR very well as there were minimal differences between the predicted and experimentally bioavailability. The parameters estimated during the model fitting represented physiological aspects of the digestion process, which were also sources of inter-individual variability. For the digestion of broccoli, the parameters that represented sources for variation between individuals were SRR, the ratio of GR converted to SR during mastication, and $k_{f}$ and $k_{\text {eni }}$, the conversion rate constants of GR to SR or other break down products. The inter-individual variability between participants was captured in the variability of some these estimates. However, it was not possible to correlate the variability between participants to specific physical 
attributes, such as chewing patterns or predominant gut microbes, as that information for the participants was not available.

The model's predicted values fit the experimental values very well, especially for the high and low myrosinase products. The lower quality of the fit for the no myrosinase product, indicates the need to improve the model's representation of microbial gut conversions. The work completed in this study is a preliminary step in creating a validated model, which, in the future, could be a useful tool in being able to predict the biological effects of SR and possibly other bioactive compounds. A future predictive model has the potential to positively influence the growing field of personalized nutrition.

Supplementary Materials: The following are available online at https:/ / www.mdpi.com/article/ 10.3390/foods10112761/s1. Table S1: Compartment Equations, Tables S2-S8: Parameter Box Plots, Figure S1: Model Fittings Results for All Participants, Matlab Codes and Simulink Model

Author Contributions: Q.S.: Conceptualization, methodology, software, investigation, writingoriginal draft preparation, visualization. M.D.: Conceptualization, methodology, writing-review and editing, supervision. All authors have read and agreed to the published version of the manuscript.

Funding: This research received no external funding.

Data Availability Statement: Not applicable.

Acknowledgments: Frank Sommerhage for his assistance with Matlab.

Conflicts of Interest: The authors declare no conflict of interest.

\section{Appendix A. Myrosinase Calculations}

The amount of myrosinase (mg MYR/mg Broccoli) was calculated based on the methods of Oliviero et al. [35] and the research of Roman et al. [42] Oliviero et al. used a spectrophotometric method to determine the myrosinase activity in the different broccoli products. Roman et al. investigated two mechanisms for substrate inhibition during the conversion of GLs to ITCs by modeling their experimental results (enzyme reaction rate vs. sinigrin concentration) using the modified Michaelis-Menten $K_{i}=$ netics with Substrate Inhibition (MMSI) model (Equation (A1)).

$$
v=\frac{V_{\max } \cdot[S]}{K_{m}+[S]+\frac{[S]^{2}}{K_{i}}}
$$

$V_{\max }\left(\mu \mathrm{M} / \min ^{*} \mathrm{mg} \mathrm{MYR}\right)$ is the maximum rate of the system, $K_{m}(\mu \mathrm{M})$ is the MichaelisMenten constant, $K_{i}(\mu \mathrm{M})$ is the inhibition constant, $S$ is the substrate concentration, and $v$ is the reaction rate. This physiological-based model assumes substrate inhibition occurs in the catalytic site.

Part I. Steps to determining myrosinase content in each broccoli product.

1. Experimental data points were extracted from the reaction rate vs. sinigrin concentration graph [42].

\begin{tabular}{cc}
\hline Sinigrin Concentration $(\mu \mathbf{M})$ & Initial Reaction Rate $(\mu \mathrm{mol} / \mathbf{m i n})$ \\
\hline 5 & 0.03 \\
10 & 0.05 \\
25 & 0.16 \\
40 & 0.24 \\
50 & 0.29 \\
75 & 0.42 \\
100 & 0.66 \\
149 & 0.58 \\
199 & 0.59 \\
248 & 0.57 \\
298 & 0.52 \\
\hline
\end{tabular}


2. The MMSI equation (Equation (A1)) was used to model the data. The parameters, $V_{m a x}, K_{m}$, and $K_{i}$, were solved by minimizing the sum of squares difference using Excel's SUMXMY2 function and solver.

\begin{tabular}{cc}
\hline \multicolumn{2}{c}{ Parameter Estimates } \\
\hline$V_{\max }$ & $0.96 \mu \mathrm{M} / \mathrm{min}$ \\
$K_{m}$ & $86.51 \mu \mathrm{M}$ \\
$K_{i}$ & $780.05 \mu \mathrm{M}$ \\
\hline
\end{tabular}

3. The specific enzyme activity of Myrosinase was calculated using information from the materials Oliviero et al. used to determine activity and the parameter estimates from step 2.

Concentration of sinigrin in reaction mixture used by Oliviero et al. to determine myrosinase activity was calculated as follows:

$$
\begin{gathered}
\frac{30 \mathrm{mg}}{\mathrm{mL}} \times \frac{\mathrm{mol}}{397.5 \mathrm{~g}} \times \frac{\mathrm{g}}{1000 \mathrm{mg}} \times 10^{6}=75.5 \frac{\mathrm{umol}}{\mathrm{mL}} \\
75.5 \frac{\mu \mathrm{mol}}{\mathrm{mL}} \times \frac{0.05 \mathrm{~mL} \text { sinigrin solution }}{1.105 \mathrm{~mL}} \times 1000 \frac{\mathrm{mL}}{\mathrm{L}} \\
=3415 \mathrm{uM} \text { Sinigrin in reaction mixture }
\end{gathered}
$$

Equation (A1) was used to calculate specific enzyme activity

$$
\frac{\left(0.96 \frac{\mu \mathrm{M}}{\mathrm{min} * \mathrm{mg} \mathrm{MYR}}\right) \times 3415 \mu \mathrm{M}}{86.51 \mu \mathrm{M}+3415 \mu \mathrm{M}+\frac{(3415 \mu \mathrm{M})^{2}}{780.05 \mu \mathrm{M}}}=0.178 \frac{\mathrm{umol}}{\mathrm{mg} \mathrm{MYR} * \min }
$$

4. The Oliviero $M Y R$ activity (column A below) for each product type was divided by $5000 \mathrm{mg}$ to determine the $\mu \mathrm{mol} \mathrm{MYR} / \mathrm{mg}$ broccoli * min (column B). Column B was divided by the specific enzyme activity $\left(0.178 \mu \mathrm{mol} / \mathrm{mg}\right.$ MYR $\left.{ }^{*} \mathrm{~min}\right)$ to obtain the $\mathrm{mg}$ MYR/mg Broccoli (column C).

\begin{tabular}{cccc}
\hline & A & B & C \\
& $\begin{array}{c}\text { MYR Activity } \\
\text { (Units/5 g dry wt Broccoli) }\end{array}$ & $\begin{array}{c}\text { Mmol/mg } \\
\text { Broccoli * min }\end{array}$ & $\begin{array}{c}\text { mg MYR/mg } \\
\text { Broccoli }\end{array}$ \\
\hline High MYR BP & 31 & 0.0062 & 0.035 \\
High MYR BF & 31 & 0.0062 & 0.035 \\
Medium MYR BF & 5.8 & 0.00116 & 0.007 \\
Low MYR BF & 0.5 & 0.0001 & 0.000563 \\
No MYR BF $(<0.01)$ & 0.01 & 0.000002 & 0.0000113 \\
\hline
\end{tabular}

Part II. Estimating $V_{\max }, K_{m}$, and $K_{i}$, for the myrosinase conversion of $G R$ in the mouth.

1. Experimental data points were extracted from the reaction rate vs. glucoraphanin concentration graph [42].

\begin{tabular}{cc}
\hline Glucoraphanin Concentration $(\mu \mathbf{M})$ & Initial Reaction Rate $(\mu \mathrm{mol} / \mathbf{m i n})$ \\
\hline 5 & 0.02 \\
8 & 0.09 \\
10 & 0.11 \\
25 & 0.25 \\
50 & 0.45 \\
75 & 0.7 \\
90 & 1.14 \\
100 & 1.33 \\
150 & 1.25 \\
200 & 1.19 \\
250 & 1.18 \\
300 & 1.05 \\
\hline
\end{tabular}


2. The MMSI equation (Equation (A1)) was used to model the data. The parameters, $V_{m a x}, K_{m}$, and $K_{i}$, were solved by minimizing the sum of squares difference using Excel's SUMXMY2 function and solver.

\begin{tabular}{cc}
\hline \multicolumn{2}{c}{ Parameter Estimates } \\
\hline$V_{\max }$ & $2070 \mu \mathrm{mol} / \mathrm{min}$ \\
$K_{m}$ & $110.16 \mu \mathrm{M}$ \\
$K_{i}$ & $893.02 \mu \mathrm{M}$ \\
\hline
\end{tabular}

\section{Appendix B. Parameter Estimates Results and Discussion for $\mathrm{K}_{\mathrm{SH}}, \mathrm{K}_{\mathrm{tSI}}, \mathrm{K}_{\mathrm{tLI}}$, and $\mathrm{K}_{\mathrm{e}}$}

Stomach emptying was described as biphasic by having two stomach compartments. The first stomach compartment was for the delay caused by the disintegration of large food particles before it is emptied into the duodenum. Delayed emptying has been observed for wheat products [59] and other solid foods [31,39]. Since participants ate a 30 -g raisin bun, right after ingesting $5 \mathrm{~g}$ of broccoli florets, a compartment was included to represent disintegration of both food products. $\mathrm{K}_{\mathrm{SH}}$, the rate constant from the first stomach compartment to the second, is the inverse of the time required for food disintegration. Parameter estimates for $\mathrm{K}_{\mathrm{SH}}$ are shown in Table A1. Excluding the outliers, HighBP $\left(\mathrm{IQR}=0.008 \mathrm{~min}^{-1}\right)$ and HighBF $\left(\mathrm{IQR}=0.004 \mathrm{~min}^{-1}\right)$, have normal distributions compared to Med, Low and NoBF products. Comparatively, the median values of HighBP $\left(0.009 \mathrm{~min}^{-1}\right)$ and High BF $\left(0.007 \mathrm{~min}^{-1}\right)$ are smaller than the medians of the MedBF $\left(0.017 \mathrm{~min}^{-1}\right)$, LowBF $\left(0.016 \mathrm{~min}^{-1}\right)$, and NoBF $\left(0.014 \mathrm{~min}^{-1}\right)$ products. These values imply that most participants who consumed MedBF, LowBF and NoBF, required less time for stomach disintegration of the broccoli and the raisin bun than HighBF and HighBP. Since all participants consumed the same amounts of florets and raisin bun, differences in food disintegration were only expected between individuals due to physiological differences. However, the median and distribution differences between the High MYR products and the remaining three were not expected. Kong et al. [60] observed longer disintegration times in their stomach model for raw and 2 min cooked carrots versus their 6 min cooked carrots. Since the high MYR broccoli florets, HighBF, were less heat processed, a harder product texture may be the cause of its longer disintegration time. However, this does not explain why the powdered product, HighBP does not have shorter disintegration times compared to the MedBF, LowBF, and NoBF. It is possible that the raisin bun consumed at the time participants consumed HighBP was harder in texture than when the other broccoli products were consumed.

The transit rate constants for each compartment of the small and large intestine are $\mathrm{k}_{\mathrm{tSI}}$ and $\mathrm{k}_{\mathrm{tLI}}$, respectively. The rate constants were determined based on the measured time it takes for food contents to transit through the small and large intestines. Excluding outliers, the distribution of $\mathrm{k}_{\mathrm{tSI}}$ parameters for MedBF $\left(\mathrm{IQR}=0.014 \mathrm{~min}^{-1}\right)$, LowBF $\left(\mathrm{IQR}=0.013 \mathrm{~min}^{-1}\right)$, and NoBF $\left(\mathrm{IQR}=0.009 \mathrm{~min}^{-1}\right.$ ) are less variable compared to the High $\mathrm{BP}\left(\mathrm{IQR}=0.098 \mathrm{~min}^{-1}\right)$ and High $\mathrm{BF}\left(\mathrm{IQR}=0.057 \mathrm{~min}^{-1}\right)$ broccoli products (Table A2). Except for MedBF (outliers excluded), the parameter distributions for the four products are positively skewed. The median values for all broccoli products are similar, around $0.02 \mathrm{~min}^{-1}$, which is within the range of literature cited values $-0.01228 \mathrm{~min}^{-1}$ $0.2333 \mathrm{~min}^{-1}$ [26]. Across all products transit through the small intestine compartments takes $50 \mathrm{~min}\left(1 / 0.02 \mathrm{~min}^{-1}\right)$ or longer for $50 \%$ of the participants. For each product, the percentage of $\mathrm{k}_{\mathrm{tSI}}$ parameter estimates that fall within the literature cited range are: $100 \%$ NoBF, $93 \%$ LowBF, $71 \%$ MedBF, $67 \%$ HighBF, and 73\% HighBP. $\mathrm{K}_{\mathrm{tLI}}$ was not fitted for the HighBP and HighBF; it was fixed at $0.003 \mathrm{~min}^{-1}$ for both products (Table A3) because sensitivity analysis showed this parameter did not have an influence on the model's output. The medians for MedBF $\left(0.280 \mathrm{~min}^{-1}\right)$, LowBF $\left(0.220 \mathrm{~min}^{-1}\right)$, and $\operatorname{NoBF}\left(0.031 \mathrm{~min}^{-1}\right)$ are larger than literature ranges $\left(0.002 \mathrm{~min}^{-1}-0.003 \mathrm{~min}^{-1}\right)$ for gut intestinal transit [61]. The parameter distributions are variable especially $\mathrm{NoBF}$ in which the interquartile range is $560 \%$ of the median. Furthermore, the distribution for NoBF is positively skewed, indicating that $50 \%$ of the participants had colon transit times longer than $32 \mathrm{~min}\left(1 / 0.031 \mathrm{~min}^{-1}\right)$ 
per compartment or $3.8 \mathrm{~h}$ for the colon. Based on the skewness, the participants with the long transit times are not as variable as the $50 \%$ of participants with transit times shorter than 32 min per compartment. Nine out of the 15 participants in the Oliviero study were women and it is known that women have longer intestinal transit times compared to men [62]. The gender of the participants with their corresponding data were not provided, so it is impossible to correlate transit times to gender.

Table A1. $\mathrm{K}_{\mathrm{SH}}$ estimation results.

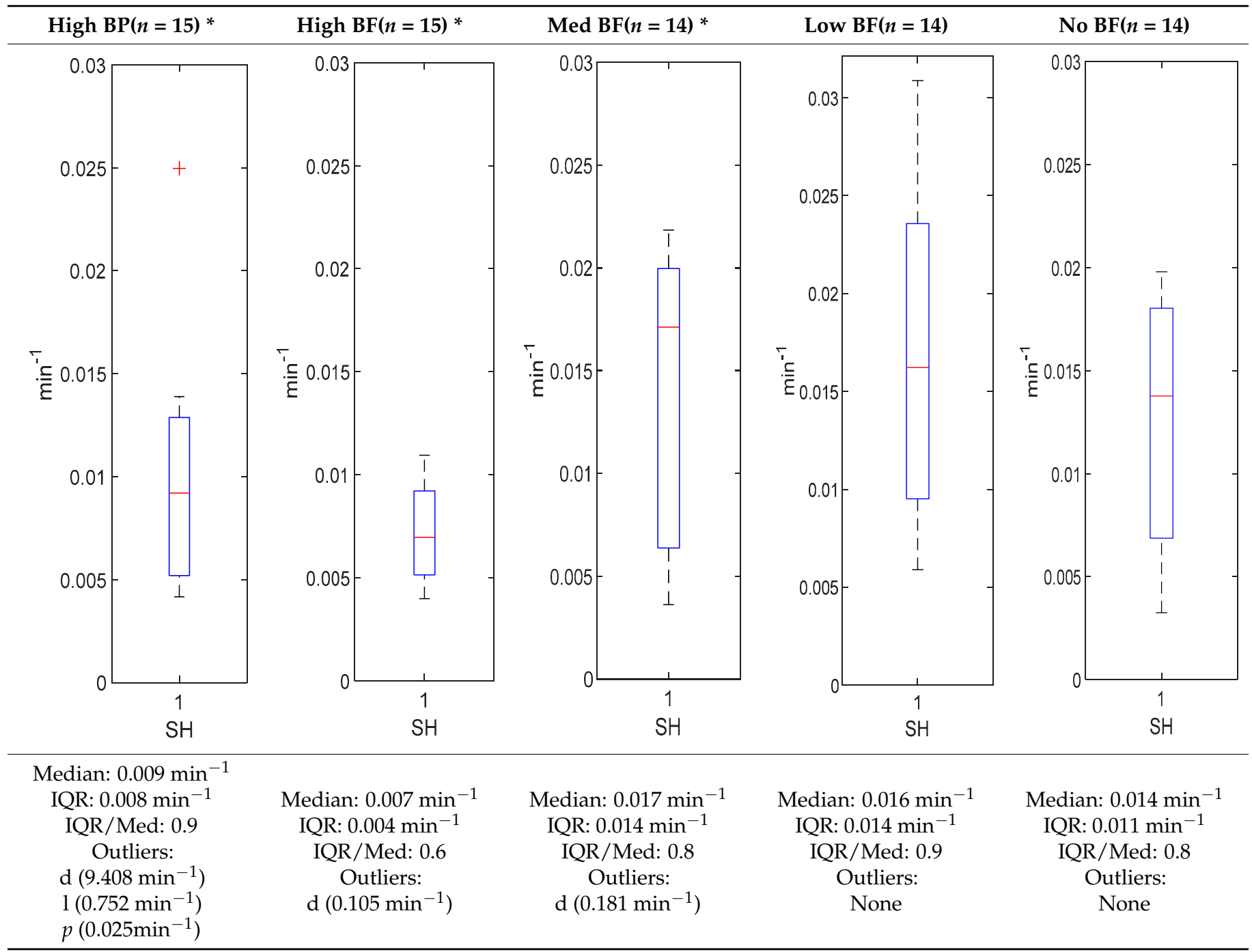

* Some or all outliers excluded for better visual presentation and comparison of boxplots. Outliers (+) are values more than 1.5 times the IQR. See supplementary tables for plotted outliers.

The rate constant for sulforaphane elimination from the blood, $\mathrm{k}_{\mathrm{e}}$, was not fitted for HighBP and HighBF products, but rather fixed at $0.024 \mathrm{~min}^{-1}$ (Table A4). The median rates of elimination for MedBF, LowBF and NoBF are $0.020 \mathrm{~min}^{-1}, 0.025 \mathrm{~min}^{-1}$, and $0.017 \mathrm{~min}^{-1}$, respectively. The IQR is largest for MedBF $\left(0.043 \mathrm{~min}^{-1}\right)$, followed by LowBF $\left(0.028 \mathrm{~min}^{-1}\right)$ and NoBF $\left(0.01 \mathrm{~min}^{-1}\right)$. Vermeulen et al. [36] fitted the plasma concentration data to one compartmental model and determined the elimination half-lives $\left(t_{0.5}\right)$ of SR for cooked and raw broccoli to be $4.6 \mathrm{~h}$ and $3.8 \mathrm{~h}$, respectively. From half-lives $\left(\mathrm{t}_{0.5}=0.693 / \mathrm{ke}\right)$, the elimination rate constants were calculated to be $0.002511 \mathrm{~min}^{-1}$ (cooked) and $0.003039 \mathrm{~min}^{-1}$ (raw) [36]. Vermeulen's values are lower than all estimated parameters of MedBF, LowBF, and NoBF products. The difference is most likely due to the method used in determining $\mathrm{k}_{\mathrm{e}}$, because Vermeulen et al. uses a more empirical model than the one described in this thesis. 
Table A2. $\mathrm{k}_{\mathrm{tSI}}$ estimation results.

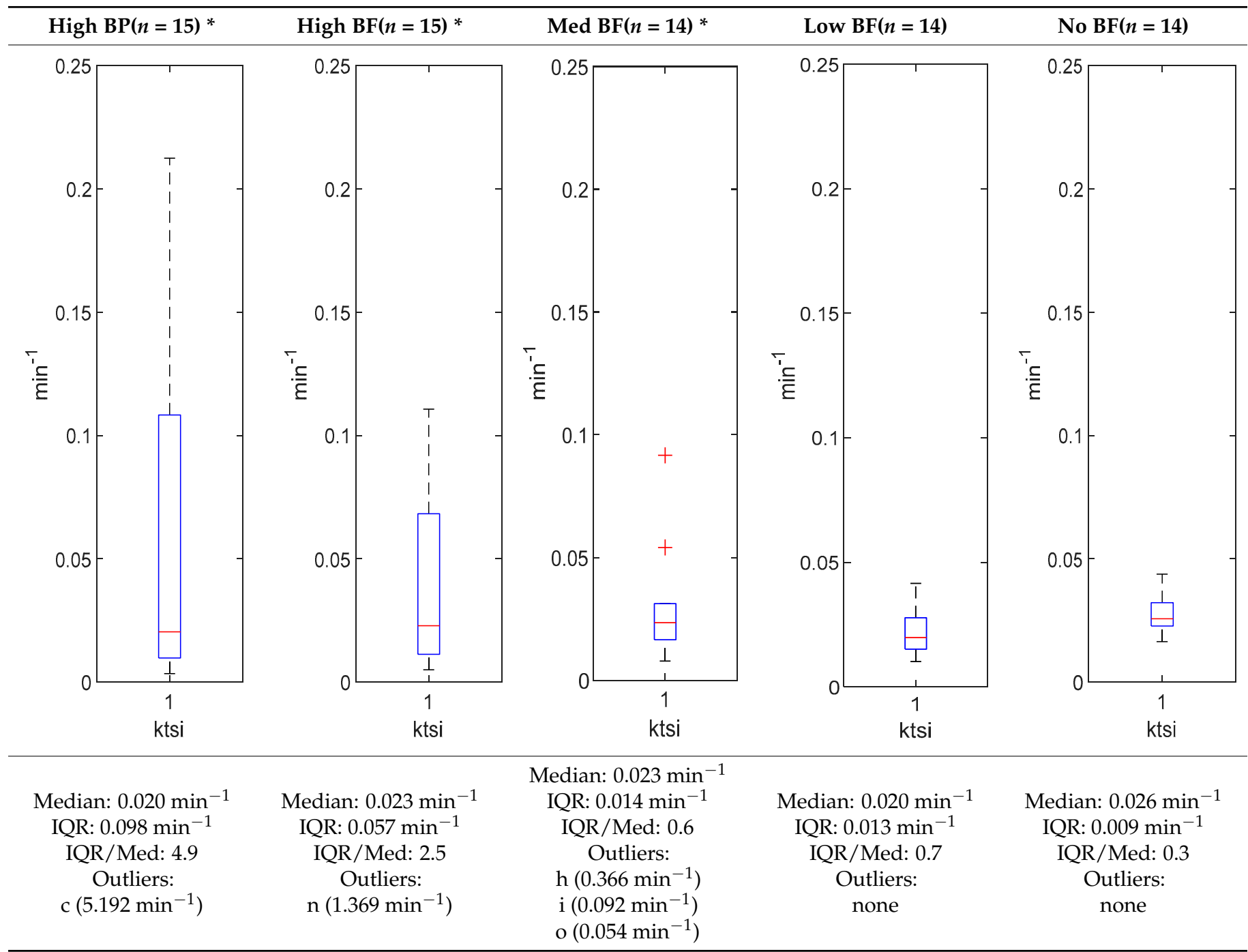

* Some or all outliers excluded for better visual presentation and comparison of boxplots. Outliers (+) are values more than 1.5 times the IQR. See supplementary tables for plotted outliers. 
Table A3. $\mathrm{k}_{\mathrm{t} L \mathrm{I}}$ estimation results.

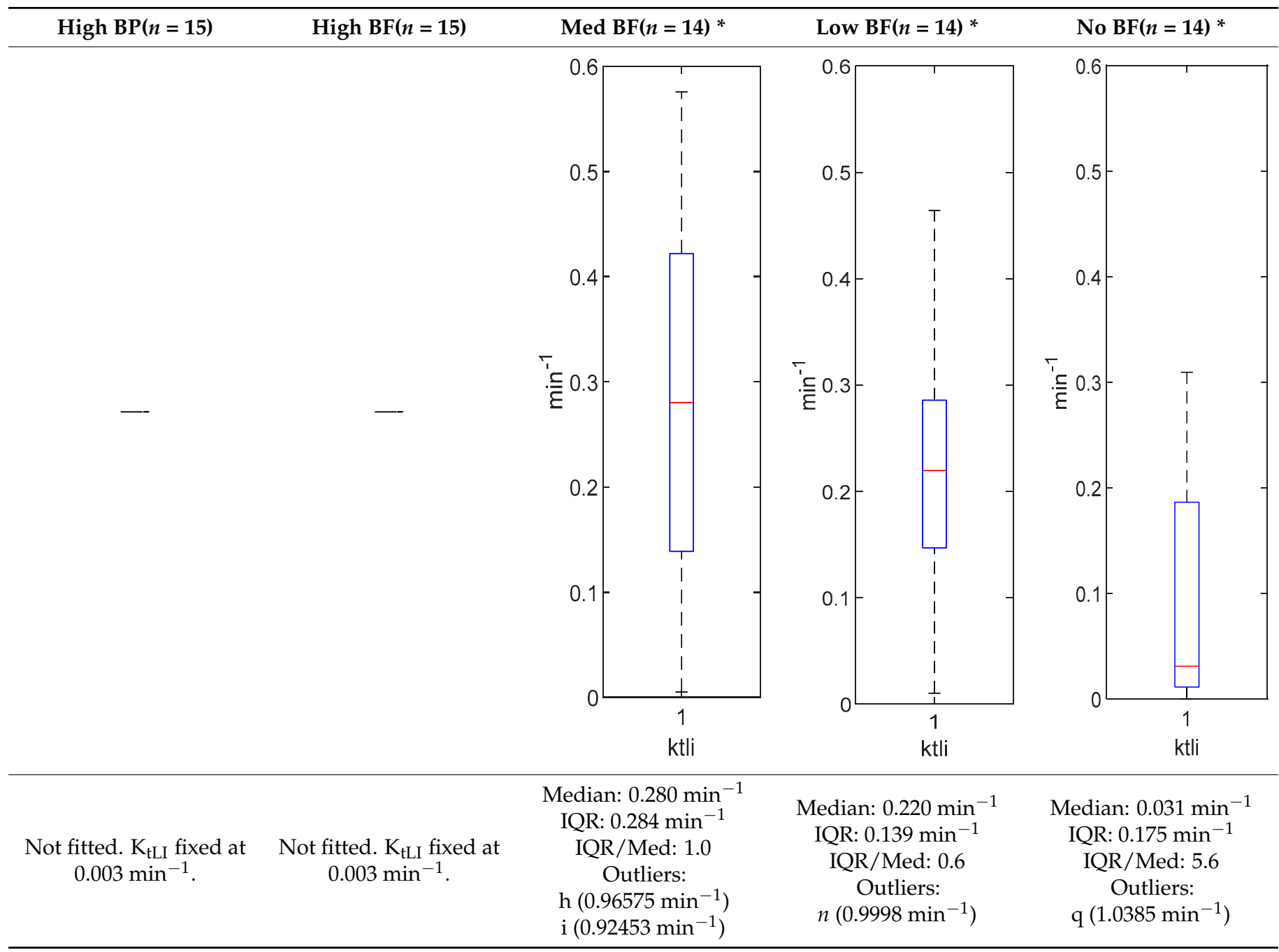

* Some or all outliers excluded for better visual presentation and comparison of boxplots. Outliers $(+)$ are values more than 1.5 times the IQR. See supplementary tables for plotted outliers. 
Table A4. $\mathrm{k}_{\mathrm{e}}$ estimation results.

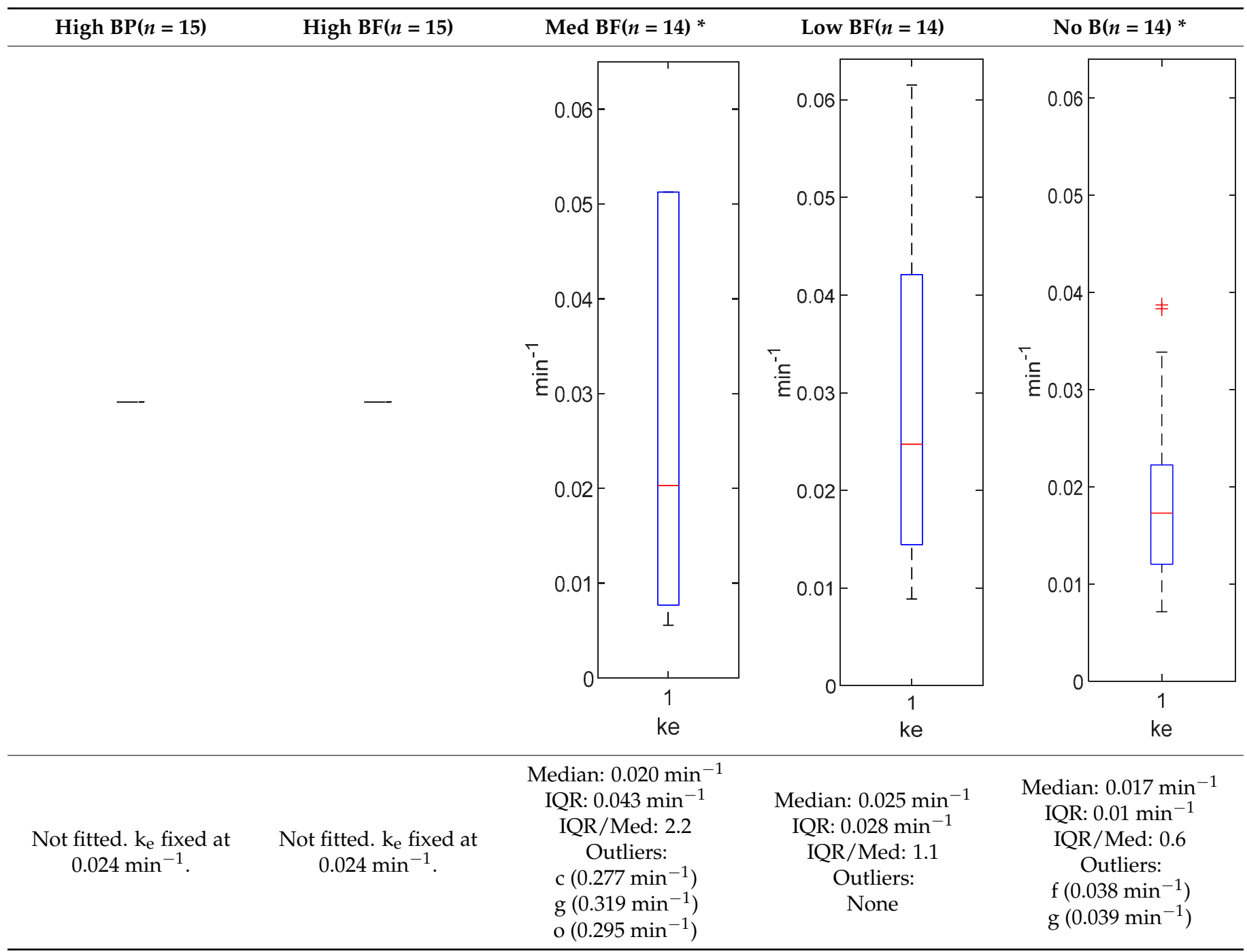

* Some or all outliers excluded for better visual presentation and comparison of boxplots. Outliers (+) are values more than 1.5 times the IQR. See supplementary tables for plotted outliers.

\section{References}

1. Mérillon, J.M.; Ramawat, K.G. Glucosinolates; Springer: Cham, Switzerland, 2017.

2. Dinkova-Kostova, A.T.; Kostov, R.V. Glucosinolates and isothiocyanates in health and disease. Trends Mol. Med. $2012,18,337-347$. [CrossRef] [PubMed]

3. Oliviero, T.; Verkerk, R.; Dekker, M. Isothiocyanates from brassica Vegetables-Effects of processing, cooking, mastication, and digestion. Mol. Nutr. Food Res. 2018, 62, e1701069. [CrossRef]

4. Verkerk, R.; Schreiner, M.; Krumbein, A.; Ciska, E.; Holst, B.; Rowland, I.; De Schrijver, R.; Hansen, M.; Gerhäuser, C.; Mithen, R.; et al. Glucosinolates in brassica vegetables: The influence of the food supply chain on intake, bioavailability and human health. Mol. Nutr. Food Res. 2009, 53, S219. [CrossRef]

5. Nugrahedi, P.Y.; Verkerk, R.; Widianarko, B.; Dekker, M. A mechanistic perspective on Process-Induced changes in glucosinolate content in brassica vegetables: A review. Crit. Rev. Food Sci. Nutr. 2015, 55, 823-838. [CrossRef]

6. Saha, S.; Hollands, W.; Teucher, B.; Needs, P.W.; Narbad, A.; Ortori, C.A.; Barrett, D.A.; Rossiter, J.T.; Mithen, R.F.; Kroon, P.A. Isothiocyanate concentrations and interconversion of sulforaphane to erucin in human subjects after consumption of commercial frozen broccoli compared to fresh broccoli. Mol. Nutr. Food Res. 2012, 56, 1906-1916. [CrossRef]

7. Li, F.; Hullar, M.A.J.; Beresford, S.A.A.; Lampe, J.W. Variation of glucoraphanin metabolism in vivo and ex vivo by human gut bacteria. Br. J. Nutr. 2011, 106, 408-416. [CrossRef] [PubMed]

8. Mullaney, J.A.; Kelly, W.J.; McGhie, T.K.; Ansell, J.; Heyes, J.A. lactic acid bacteria convert glucosinolates to nitriles efficiently yet differently from enterobacteriaceae. J. Agric. Food Chem. 2013, 61, 3039-3046. [CrossRef] [PubMed]

9. Narbad, A.; Rossiter, J.T. Gut glucosinolate metabolism and isothiocyanate production. Mol. Nutr. Food Res. 2018, 62, e1700991. [CrossRef] 
10. Palop, M.L.; Smiths, J.P.; ten Brink, B. Degradation of sinigrin by Lactobacillus agilis strain R16. Int. J. Food Microbiol. 1995, 26, 219-229. [CrossRef]

11. Rabot, S.; Guerin, C.; Nugon-Baudon, L.; Szylit, O. Glucosinolate degradation by bacterial strains isolated from a human intestinal microflora. In 9th International Rapeseed Congress; GCIRC: Cambridge, UK; Paris, France, 1995.

12. Elfoul, L.; Rabot, S.; Khelifa, N.; Quinsac, A.; Duguay, A.; Rimbault, A. Formation of allyl isothiocyanate from sinigrin in the digestive tract of rats monoassociated with a human colonic strain of Bacteroides thetaiotaomicron. FEMS Microbiol. Lett. 2001, 197, 99-103. [CrossRef]

13. Luang-In, V.; Narbad, A.; Nueno-Palop, C.; Mithen, R.; Bennett, M.; Rossiter, J.T. The metabolism of methylsulfinylalkyl- and methylthioalkyl-glucosinolates by a selection of human gut bacteria. Mol. Nutr. Food Res. 2014, 58, 875-883. [CrossRef] [PubMed]

14. Cheng, D.L.; Hashimoto, K.; Uda, Y. In vitro digestion of sinigrin and glucotropaeolin by single strains of Bifidobacterium and identification of the digestive products. Food Chem. Toxicol. 2004, 42, 351-357. [CrossRef] [PubMed]

15. Kühn, C.; Kupke, F.; Baldermann, S.; Klopsch, R.; Lamy, E.; Hornemann, S.; Pfeiffer, A.F.H.; Schreiner, M.; Hanschen, F.S.; Rohn, S. Diverse excretion pathways of benzyl glucosinolate in humans after consumption of nasturtium (Tropaeolum majus L.) - A pilot study. Mol. Nutr. Food Res. 2018, 62, 1800588. [CrossRef] [PubMed]

16. Rein, M.J.; da Silva Pinto, M. Improvement of bioaccessibility and bioavailability: From molecular interactions to delivery systems. In Engineering Foods for Bioactives Stability and Delivery; Roos, Y.H., Livney, Y.D., Eds.; Springer: New York, NY, USA, 2017; pp. 401-416.

17. Capuano, E.; Pellegrini, N. An integrated look at the effect of structure on nutrient bioavailability in plant foods. J. Sci. Food Agric. 2019, 99, 493-498. [CrossRef]

18. Aguilera, J.M. The food matrix: Implications in processing, nutrition and health. Crit. Rev. Food Sci. Nutr. 2019, 59, 3612-3629. [CrossRef]

19. Sarvan-Kruse, I.; Kramer, E.; Bouwmeester, H.; Dekker, M.; Verkerk, R. Sulforaphane formation and bioaccessibility are more affected by steaming time than meal composition during in vitro digestion of broccoli. Food Chem. 2017, 214, 580-586. [CrossRef]

20. Sarvan, I.; van der Klauw, M.; Oliviero, T.; Dekker, M.; Verkerk, R. The effect of chewing on oral glucoraphanin hydrolysis in raw and steamed broccoli. J. Funct. Foods 2018, 45, 306-312. [CrossRef]

21. Hanschen, F.S.; Kühn, C.; Nickel, M.; Rohn, S.; Dekker, M. Leaching and degradation kinetics of glucosinolates during boiling of Brassica oleracea vegetables and the formation of their breakdown products. Food Chem. 2018, 263, 240-250. [CrossRef]

22. Matusheski, N.V.; Juvik, J.A.; Jeffery, E.H. Heating decreases epithiospecifier protein activity and increases sulforaphane formation in broccoli. Phytochemistry 2004, 65, 1273-1281. [CrossRef]

23. Hutchings, S.C.; Foster, K.D.; Bronlund, J.E.; Lentle, R.G.; Jones, J.R.; Morgenstern, M.P. Mastication of heterogeneous foods: Peanuts inside two different food matrices. Food Qual. Prefer. 2011, 22, 332-339. [CrossRef]

24. Shapiro, T.A.; Fahey, J.W.; Wade, K.L.; Stephenson, K.K.; Talalay, P. Chemoprotective glucosinolates and isothiocyanates of broccoli sprouts. Cancer Epidemiol. Biomark. 2001, 10, 501.

25. Feunteun, S.L.; Al-Razaz, A.; Dekker, M.; George, E.; Laroche, B.; Van Aken, G. Physiologically based modeling of food digestion and intestinal microbiota: State of the art and future challenges. An INFOGEST review. Annu. Rev. Food Sci. Technol. 2021, 12, 149-167. [CrossRef] [PubMed]

26. Yu, L.X.; Crison, J.R.; Amidon, G.L. Compartmental transit and dispersion model analysis of small intestinal transit flow in humans. Int. J. Pharm. 1996, 140, 111-118. [CrossRef]

27. Huang, W.; Lee, S.L.; Yu, L.X. Mechanistic approaches to predicting oral drug absorption. AAPS J. 2009, 11, 217-224. [CrossRef]

28. Yu, L.X. An integrated model for determining causes of poor oral drug absorption. Pharm. Res. 1999, 16, 1883-1887. [CrossRef] [PubMed]

29. Punt, A.; Paini, A.; Boersma, M.G.; van Bladeren, P.J.; Rietjens, I.M.C.M.; Delatour, T.; Scholz, G.; Schilter, B.; Freidig, A.P. Use of physiologically based biokinetic (PBBK) modeling to study estragole bioactivation and detoxification in humans as compared with male rats. Toxicol. Sci. 2009, 110, 255-269. [CrossRef]

30. Punt, A.; Freidig, A.P.; Delatour, T.; Scholz, G.; Boersma, M.G.; Schilter, B.; van Bladeren, P.J.; Rietjens, I.M.C.M. A physiologically based biokinetic (PBBK) model for estragole bioactivation and detoxification in rat. Toxicol. Appl. Pharmacol. 2008, 231, 248-259. [CrossRef]

31. Le Feunteun, S.; Barbé, F.; Rémond, D.; Ménard, O.; Le Gouar, Y.; Dupont, D.; Laroche, B. Impact of the dairy matrix structure on milk protein digestion kinetics: Mechanistic modelling based on mini-pig in vivo data. Food Bioprocess. Technol. 2014, 7, 1099-1113. [CrossRef]

32. Strathe, A.B.; Danfær, A.; Chwalibog, A. A dynamic model of digestion and absorption in pigs. Anim. Feed. Sci. Technol. 2008, 143, 328-371. [CrossRef]

33. Moxon, T.E.; Gouseti, O.; Bakalis, S. In silico modelling of mass transfer \& absorption in the human gut. J. Food Eng. 2016, 176, 110-120.

34. Li, Y.; Zhang, T.; Li, X.; Zou, P.; Schwartz, S.J.; Sun, D. Kinetics of sulforaphane in mice after consumption of sulforaphane-enriched broccoli sprout preparation. Mol. Nutr. Food Res. 2013, 57, 2128-2136. [CrossRef]

35. Oliviero, T.; Verkerk, R.; Vermeulen, M.; Dekker, M. In vivo formation and bioavailability of isothiocyanates from glucosinolates in broccoli as affected by processing conditions. Mol. Nutr. Food Res. 2014, 58, 1447-1456. [CrossRef] 
36. Vermeulen, M.; Klöpping-Ketelaars, I.W.; van den Berg, R.; Vaes, W.H. Bioavailability and kinetics of sulforaphane in humans after consumption of cooked versus raw broccoli. J. Agric. Food Chem. 2008, 56, 10505-10509. [CrossRef] [PubMed]

37. Vermeulen, M.; van Rooijen, H.J.; Vaes, W.H. Analysis of isothiocyanate mercapturic acids in urine: A biomarker for cruciferous vegetable intake. J. Agric. Food Chem. 2003, 51, 3554-3559. [CrossRef] [PubMed]

38. Sreebny, L.M. Saliva in health and disease: An appraisal and update. Int. Dent. J. 2000, 50, 140-161. [CrossRef] [PubMed]

39. Siegel, J.A.; Urbain, J.L.; Adler, L.P.; Charkes, N.D.; Maurer, A.H.; Krevsky, B.; Knight, L.C.; Fisher, R.S.; Malmud, L.S. Biphasic nature of gastric emptying. Gut 1988, 29, 85-89. [CrossRef] [PubMed]

40. Mahn, A.; Angulo, A.; Cabañas, F. Purification and characterization of broccoli (Brassica oleracea var. italica) Myrosinase ( $\beta$ Thioglucosidase Glucohydrolase). J. Agric. Food Chem. 2014, 62, 11666-11671. [CrossRef] [PubMed]

41. Lennernäs, H. Intestinal permeability and its relevance for absorption and elimination. Xenobiotica 2007, 37, 1015-1051. [CrossRef] [PubMed]

42. Román, J.; Castillo, A.; Cottet, L.; Mahn, A. Kinetic and structural study of broccoli myrosinase and its interaction with different glucosinolates. Food Chem. 2018, 254, 87-94. [CrossRef] [PubMed]

43. Watanabe, S.; Dawes, C. A comparison of the effects of tasting and chewing foods on the flow rate of whole saliva in man. Arch. Oral Biol. 1988, 33, 761-764. [CrossRef]

44. Bornhorst, G.M.; Singh, R.P. Bolus formation and disintegration during digestion of food carbohydrates. Compr. Rev. Food Sci. Food Saf. 2012, 11, 101-118. [CrossRef]

45. Van Liere, E.J.; Sleeth, C.K.; Northup, D. The Relation of the size of the meal to the emptying time of the human stomach. Am. J. Physiol.-Leg. Content 1937, 119, 480-482. [CrossRef]

46. Yu, A.; Jackson, T.; Tsume, Y.; Koenigsknecht, M.; Wysocki, J.; Marciani, L.; Amidon, G.L.; Frances, A.; Baker, J.R.; Hasler, W.; et al. Mechanistic fluid transport model to estimate gastrointestinal fluid volume and its dynamic change over time. AAPS J. 2017, 19, 1682-1690. [CrossRef]

47. Helander, H.F.; Fändriks, L. Surface area of the digestive tract-revisited. Scand. J. Gastroenterol. 2014, 49, 681-689. [CrossRef]

48. Weiss, C.; Jelkmann, W. Functions of the blood. In Human Physiology; Schmidt, R.F., Thews, G., Eds.; Springer: Berlin/Heidelberg, Germany, 1989; pp. 402-438.

49. Louis, L.; Harvey, W. Predicting oral drug absorption: Mini review on physiologically-based pharmacokinetic models. Pharmaceutics 2017, 9, 41.

50. Oliviero, T.; Lamers, S.; Capuano, E.; Dekker, M.; Verkerk, R. Bioavailability of isothiocyanates from broccoli sprouts in protein, lipid, and fiber gels. Mol. Nutr. Food Res. 2018, 62, 1447-1456. [CrossRef]

51. Conaway, C.C.; Getahun, S.M.; Liebes, L.L.; Pusateri, D.J.; Topham, D.K.; Botero-Omary, M.; Chung, F.L. Disposition of glucosinolates and sulforaphane in humans after ingestion of steamed and fresh broccoli. Nutr. Cancer 2000, 38, 168-178. [CrossRef] [PubMed]

52. Yu, L.X.; Amidon, G.L. A compartmental absorption and transit model for estimating oral drug absorption. Int. J. Pharm. 1999, 186, 119-125. [CrossRef]

53. Charron, C.S.; Vinyard, B.T.; Ross, S.A.; Seifried, H.E.; Jeffery, E.H.; Novotny, J.A. Absorption and metabolism of isothiocyanates formed from broccoli glucosinolates: Effects of BMI and daily consumption in a randomised clinical trial. Br. J. Nutr. 2018, 120, 1370-1379. [CrossRef]

54. Dominianni, C.; Sinha, R.; Goedert, J.J.; Pei, Z.; Yang, L.; Hayes, R.B.; Ahn, J. Sex, body mass index, and dietary fiber intake influence the human gut microbiome. PLoS ONE 2015, 10, e0124599. [CrossRef] [PubMed]

55. Haro, C.; Rangel-Zúñiga, O.A.; Alcalá-Díaz, J.F.; Gómez-Delgado, F.; Pérez-Martínez, P.; Delgado-Lista, J.; Quintana-Navarro, G.M.; Landa, B.B.; Navas-Cortés, J.A.; Tena-Sempere, M.; et al. Intestinal Microbiota Is Influenced by Gender and Body Mass Index. PLoS ONE 2016, e0154090. [CrossRef]

56. Tani, N.; Ohtsuru, M.; Hata, T. Isolation of myrosinase producing microorganism. Agric. Biol. Chem. 1974, 38, 1617-1622. [CrossRef]

57. Luang-In, V.; Narbad, A.; Cebeci, F.; Bennett, M.; Rossiter, J.T. Identification of proteins possibly involved in glucosinolate metabolism in L. agilis R16 and E. coli VL8. Protein J. 2015, 34, 135-146. [CrossRef] [PubMed]

58. Liou, C.S.; Sirk, S.J.; Diaz, C.A.C.; Klein, A.P.; Fischer, C.R.; Higginbottom, S.K.; Erez, A.; Donia, M.S.; Sonnenburg, J.L.; Sattely, E.S. A Metabolic pathway for activation of dietary glucosinolates by a human gut symbiont. Cell 2020, 180, 717-728. [CrossRef] [PubMed]

59. Bornhorst, G.; Singh, R.; Heldman, D. Rate kinetics of bread bolus disintegration during in vitro digestion. In International Congress of Engineering and Food; Elsevier Procedia: Amsterdam, The Netherlands, 2011.

60. Kong, F.; Singh, R.P. A model stomach system to investigate disintegration kinetics of solid foods during gastric digestion. J. Food Sci. 2008, 73, 202-210. [CrossRef]

61. Basile, M.; Neri, M.; Carriero, A.; Casciardi, S.; Comani, S.; Del Gratta, C.; Di Donato, L.; Di Luzio, S.; Macri, M.A.; Pasquarelli, A.; et al. Measurement of segmental transit through the gut in man. A novel approach by the biomagnetic method. Dig. Dis. Sci. 1992, 37, 1537-1543. [CrossRef]

62. Degen, L.P.; Phillips, S.F. Variability of gastrointestinal transit in healthy women and men. Gut 1996, 39, 299. [CrossRef] 